\section{Evaluating Renewable Portfolio Standards and Carbon Cap Scenarios in the U.S. Electric Sector}

Lori Bird, Caroline Chapman, Jeff Logan, Jenny Sumner, and Walter Short

\section{Technical Report} NREL/TP-6A2-48258

May 2010

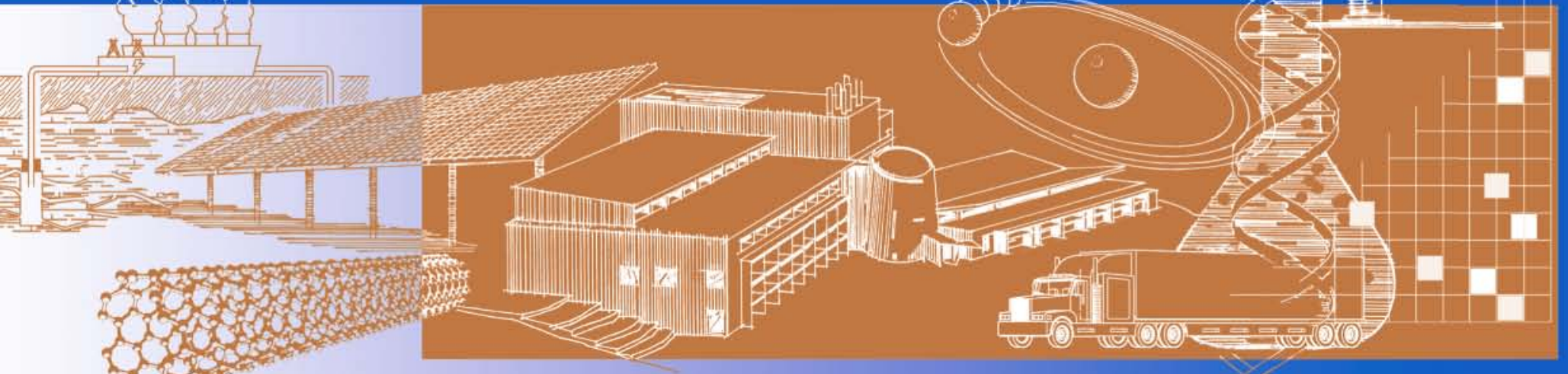


Evaluating Renewable

Portfolio Standards and

Carbon Cap Scenarios in the U.S. Electric Sector

Lori Bird, Caroline Chapman, Jeff Logan, Jenny Sumner, and Walter Short

Prepared under Task No. SAO9.2038
Technical Report NREL/TP-6A2-48258

May 2010

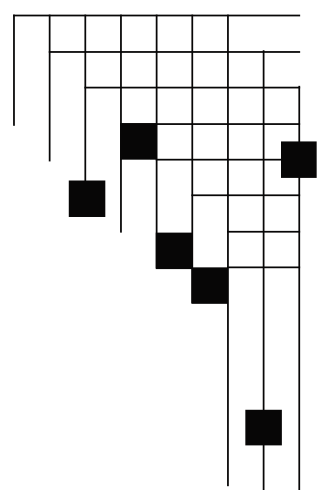




\section{NOTICE}

This report was prepared as an account of work sponsored by an agency of the United States government. Neither the United States government nor any agency thereof, nor any of their employees, makes any warranty, express or implied, or assumes any legal liability or responsibility for the accuracy, completeness, or usefulness of any information, apparatus, product, or process disclosed, or represents that its use would not infringe privately owned rights. Reference herein to any specific commercial product, process, or service by trade name, trademark, manufacturer, or otherwise does not necessarily constitute or imply its endorsement, recommendation, or favoring by the United States government or any agency thereof. The views and opinions of authors expressed herein do not necessarily state or reflect those of the United States government or any agency thereof.

Available electronically at http://www.osti.gov/bridge

Available for a processing fee to U.S. Department of Energy and its contractors, in paper, from:

U.S. Department of Energy

Office of Scientific and Technical Information

P.O. Box 62

Oak Ridge, TN 37831-0062

phone: 865.576 .8401

fax: 865.576 .5728

email: mailto:reports@adonis.osti.gov

Available for sale to the public, in paper, from:

U.S. Department of Commerce

National Technical Information Service

5285 Port Royal Road

Springfield, VA 22161

phone: 800.553 .6847

fax: 703.605.6900

email: orders@ntis.fedworld.gov

online ordering: http://www.ntis.gov/ordering.htm 


\section{Acknowledgments}

This work was funded by the U.S. Department of Energy's Strategic Planning and Analysis Division of the Office of Energy Efficiency and Renewable Energy. The authors wish to thank David Rogers, Rebecca Garland, and Carla Frisch for their support of this work. The authors also wish to thank the following individuals for their thoughtful review comments: Jeff Deyette of the Union of Concerned Scientists; Kevin Eckerle of New West Technologies; Jenna Goodward and Eliot Metzger of the World Resources Institute; Christopher Namovicz of Energy Information Administration; Jim Newcomb, Robin Newmark, Daniel Steinberg, Laura Vimmerstedt of NREL; Anthony Paul and Karen Palmer of Resources for the Future; and Linda Silverman of the U.S. Department of Energy. Finally, the authors wish to thank Lisa Teman of All the Right Words for providing editorial support. 


\section{List of Acronyms}

ACES Act

AEO

CCS

CEC

CERES

CES

$\mathrm{CO}_{2}$

CPUC

CSP

DSIRE

EIA

ETS

EU

GHG

ITC

MWh

NERC

NEMS

PTC

PV

REC

ReEDS

RES

RGGI

RPS

TWh

UCS

WCI
American Clean Energy and Security Act of 2009

Annual Energy Outlook

carbon capture and sequestration

California Energy Commission

combined efficiency and renewable electricity

standard

clean energy standard

carbon dioxide

California Public Utilities Commission

concentrating solar power

Database of State Incentives for Renewables and

Efficiency

Energy Information Administration

Emissions Trading Scheme (European Union)

European Union

greenhouse gas

investment tax credit

megawatt hour

North American Electric Reliability Corporation

National Energy Modeling System

production tax credit

photovoltaic

renewable energy certificate

Regional Energy Deployment System

renewable electricity standard

Regional Greenhouse Gas Initiative

renewable portfolio standards

terawatt hour

Union of Concerned Scientists

Western Climate Initiative 


\section{Executive Summary}

This report examines the impact of various renewable portfolio standards (RPS) and cap-andtrade policy options on the U.S. electricity sector, focusing mainly on renewable energy generation. The analysis uses the National Renewable Energy Laboratory's Regional Energy Deployment System (ReEDS) model that simulates the least-cost expansion of electricity generation capacity and transmission in the United States to examine the impact of an emissions cap — similar to that proposed in the Waxman-Markey bill (H.R. 2454) — as well as lower and higher cap scenarios. It also examines the effects of combining various RPS targets with the emissions caps. The generation mix, carbon emissions, and electricity price are examined for various policy combinations to simulate the effect of implementing policies simultaneously.

This analysis examines RPS scenarios with renewable energy targets of $15 \%, 20 \%$, and $25 \%$ of electricity sales by 2020 . The $15 \%$ RPS scenario modeled here remains fixed at $15 \%$ after 2020 ; and the $20 \%$ and $25 \%$ RPS targets continue to increase by $1 \%$ annually through 2030 . The RPS scenarios considered in this analysis are more stringent than comparable nominal targets in recently proposed legislation, because recently proposed bills have exclusions (e.g., exempting small utilities from the requirement; allowing efficiency to substitute for renewables to meet targets) that reduce the effective renewable energy targets. These types of exclusions were not modeled. All of the RPS scenarios examined here include a load-reduction component from energy savings, because most of the recent federal RPS legislative proposals also include substantial energy-efficiency provisions.

Several alternative cap scenarios are analyzed in conjunction with RPS. The base cap considered here is a $17 \%$ reduction of 2005 greenhouse gas (GHG) emissions by 2020 , and $42 \%$ reduction of 2005 GHG emissions by 2030, with offsets and banking, consistent with the Waxman-Markey bill passed by the House in June 2009. High and low caps also were evaluated. In this analysis, "low cap" refers to a cap that is $20 \%$ less restrictive than the Waxman-Markey cap-it allows more carbon to be emitted - and the "high cap" is $20 \%$ more restrictive.

This analysis also examines implementation issues stemming from the simultaneous operation of an RPS and a carbon cap-and-trade system, such as the overlap of renewable energy certificate (REC) and carbon markets, and the treatment of REC imports under regional cap-and-trade programs. The Regional Greenhouse Gas Initiative (RGGI) and the European Union's Emissions Trading Scheme (ETS) provide limited experience with these overlapping policies and experience in these regions is briefly examined. Policy design details can vary, however, and the specific design determines the level of interaction and impact of simultaneously implementing future RPS and carbon emissions caps. The key findings are listed below.

- A carbon emissions cap and an RPS can be complementary policies that can achieve similar ends, although one policy is designed to reduce carbon emissions and the other is designed to increase renewable generation. In some cases, carbon caps have been implemented as backstops to ensure that emissions-reduction goals are met, together with relying on the implementation of technology and sector-specific policies such as RPS, efficiency standards, and other policies to encourage specific low-carbon solutions. 
- A base cap alone drives significant renewable generation but at higher electricity prices than scenarios that include load reduction from energy efficiency. The cap alone case results in 19\% non-hydro renewable energy generation in 2020 and $40 \%$ in 2030 . When the cap is combined with load reduction from energy efficiency, the fraction of non-hydro renewable generation is $16 \%$ and $38 \%$ in 2020 and 2030, respectively. The scenarios that include load reduction achieved through energy-efficiency measures minimize electricity price impacts. For example, in 2020, the electricity price of the cap alone case is $4 \%$ higher than the case of the cap with load reduction from efficiency. It is important to note, however, that the energy-efficiency measures considered could have costs that are not captured in the analysis, including costs (such as those to building owners) that are not reflected in electricity prices. The benefits of efficiency measures in terms of bill savings are also not analyzed.

- A 25\% RPS results in similar emissions levels as the base cap in the near term at similar electricity price. The adoption of a $25 \%$ RPS along with efficiency measures would put the electricity sector on a trajectory to meet the base emission cap levels in the 2020 timeframe at a similar electricity price. A RPS, however, does not provide a carbon price signal that would influence longer-term investment decisions based on a carbon-emissions basis or provide the same level of certainty of emissions reductions, particularly if electricity demand increases. Renewable portfolio standards primarily address the contribution of renewable generation in the resource mix without focusing on the mix of coal, gas, and other technologies. The emissions benefits also are similar only in the next decade or so; emissions levels diverge after the 2020 timeframe, when the cap scenarios lead to less coal generation and, consequently, lower emissions than the $25 \%$ RPS scenario.

- Renewable portfolio standards combined with emissions caps could drive renewable energy generation beyond that achieved by emissions caps alone, particularly in the near term. The RPS targets considered in the analysis when combined with emissions caps and efficiency drive significant additional renewable generation in the 2015-2020 timeframe, except in the low-(15\%) RPS case combined with a cap. In the 2030 timeframe, the emissions cap drives significant renewable generation, generally greater than required by the RPS targets considered. The modeling conducted here does not capture the investment certainty that RPS policies could provide through fixed targets - which can be important, particularly for achieving greater future penetration levels, even when caps are present.

- Combining an RPS with a base cap does not lead to substantially greater electricity prices. Incorporating higher RPS targets in conjunction with a base cap results in slight electricity price differences. The RPS and efficiency (no cap) scenarios also result in electricity prices below the reference case in the 2025-2030 timeframe. For example, the electricity price for the $25 \%$ RPS plus efficiency case is $2 \%$ below the reference case in 2030. 
- The addition of an RPS and efficiency to a base cap results in a reduction in carbon dioxide $\left(\mathrm{CO}_{2}\right)$ allowance prices. This analysis shows a substantial reduction in $\mathrm{CO}_{2}$ allowance prices in most years when an RPS and load-reduction measures are added to a base cap, because compliance costs are shared by the other policies and some costs are shifted to the REC price. The effect is more pronounced for a $25 \%$ RPS than for lower RPS levels. Similarly, this analysis shows a substantial reduction in REC prices when an emissions cap also is placed on the electric sector, where the cap shares a portion of the burden in meeting the RPS. 


\section{Table of Contents}

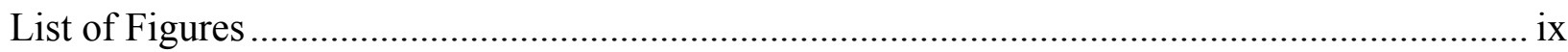

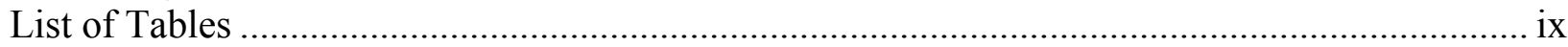

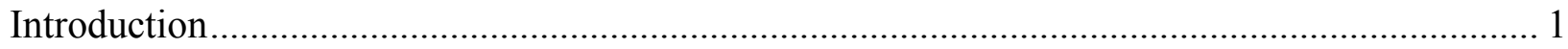

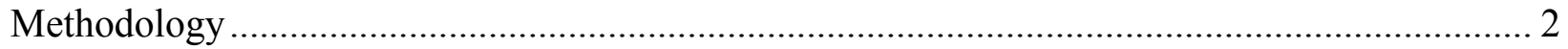

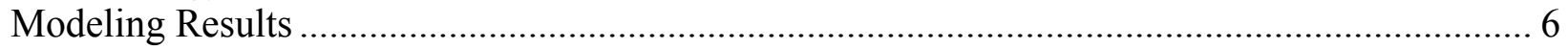

Emissions Cap and Renewable Portfolio Standards-Individually and Combined .................... 6

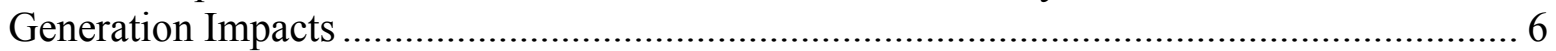

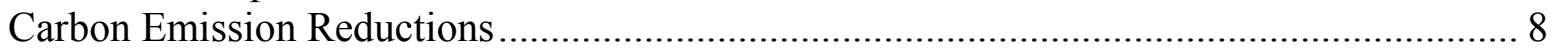

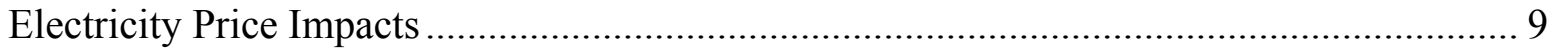

Effect of Varying Carbon Cap Levels ................................................................................. 10

Generation Impacts ................................................................................................... 10

Electricity Price Impacts, Carbon Dioxide, and Renewable Energy Credit Prices .............. 11

Effect of Varying Renewable Portfolio Standard Levels ......................................................... 13

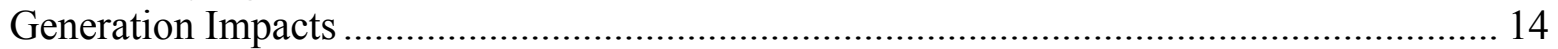

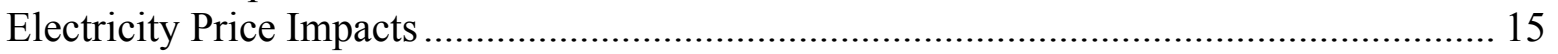

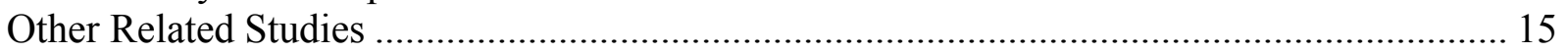

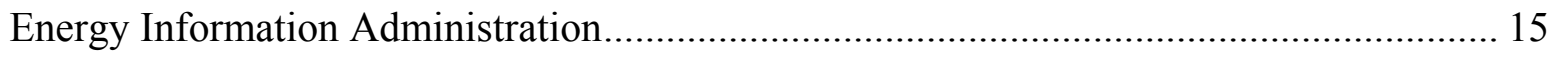

Union of Concerned Scientists........................................................................................ 17

Simultaneous Implementation of a Carbon Cap and a Renewable Portfolio Standard:

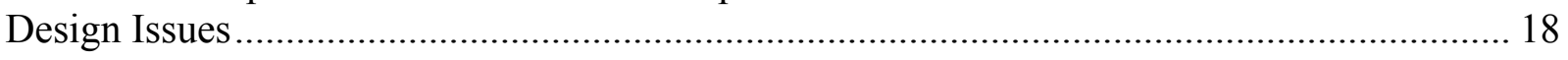

Policy Objectives and Assessing the Need for Combined Policies ........................................... 18

Recent Experience with Simultaneous Implementation of Carbon Dioxide Caps and

Renewable Portfolio Standards.................................................................................... 19

Regional Greenhouse Gas Initiative ................................................................................. 20

European Union Emissions Trading System ................................................................. 20

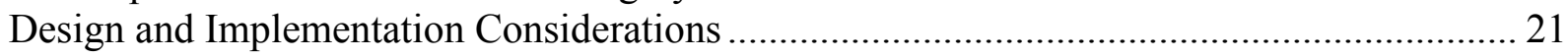

Renewable Energy Certificate and Carbon Dioxide Allowance Interaction ......................... 21

Importing Renewable Energy Certificates from Outside of the Capped Region.................... 23

Resource Eligibility and "Double Dipping" ......................................................................... 24

Trading and Tracking....................................................................................................... 24

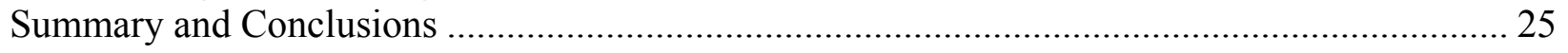

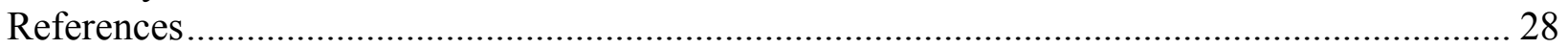

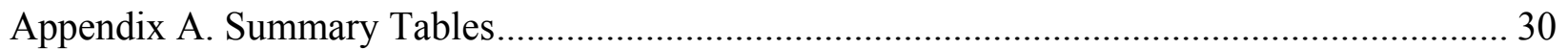




\section{List of Figures}

Figure 1. Levelized cost of electricity inputs used in ReEDS ..................................................... 5

Figure 2. Electric generation mix with RPS and cap, individually and combined in

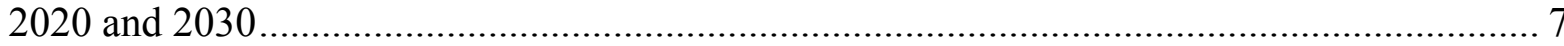

Figure 3. Carbon dioxide emissions levels for cap and RPS scenarios ....................................... 9

Figure 4. National average electricity price for cap and RPS scenarios (\$2009) ......................... 10

Figure 5. Generation mix resulting from low- and high-cap scenarios with 25\% RPS................. 11

Figure 6. Electricity prices resulting from a 25\% RPS with varying cap levels (2009\$) ............. 12

Figure 7. Renewable energy credit prices for 25\% RPS and cap scenarios (2009\$) .................... 13

Figure 8. Generation mix resulting from various RPS levels and carbon dioxide cap ................. 14

Figure 9. Electricity prices for cap and varying RPS targets (2009\$) ……………………......... 15

Figure 10. Renewable portfolio standard compliance in H.R. 2454 .......................................... 16

Figure 11. Renewable energy generation mix in the UCS study .............................................. 18

\section{List of Tables}

Table 1. Description of the Scenarios ...................................................................................... 4

Table 2. Electric Generation Mix with RPS and Cap, Individually and

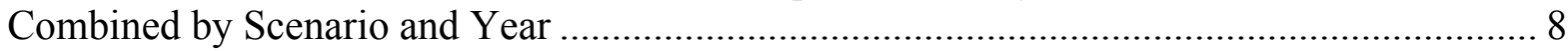

Table 3. Generation Mix by Cap Level and Year ...................................................................... 11

Table 4. Carbon Dioxide and REC Prices for Cap and RPS Scenarios ........................................ 13

Table 5. Generation Mix Resulting by RPS Level with Cap and Year ........................................ 14

Table 6. State Rules on Retiring Carbon Allowances with RECs Used for

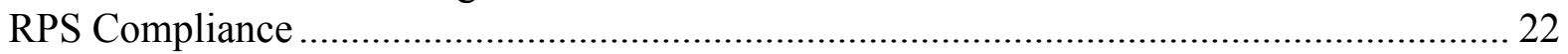

Table A-1. Electric Generation Mix with RPS/Cap Individually and Combined by Scenario

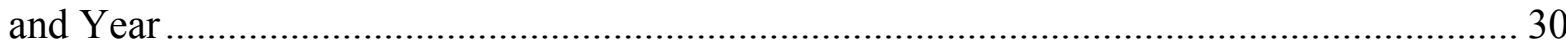

Table A-2. Electric Generation Mix by Cap Level and Year ....................................................... 31

Table A-3. Electric Generation Mix by RPS Level with Cap and Year ........................................ 32 


\section{Introduction}

Congress has recently considered the implementation of a federal carbon cap-and-trade system in conjunction with a renewable portfolio standard (RPS), also known as a renewable electricity standard (RES). The Waxman-Markey bill, (American Clean Energy and Security Act of 2009 H.R. 2454), passed by the House in June 2009, contains provisions for both a cap-and-trade system and a RPS. In the Senate, separate RPS and carbon cap-and-trade bills currently are pending floor action: the Bingaman bill, S. 1462, contains a national RPS provision, ${ }^{1}$ and the Kerry-Lieberman discussion draft introduced in May 2010 following the earlier Kerry-Boxer bill, S. 1733, establish a carbon cap-and-trade system. The energy and climate bills could be combined at some later stage. A third bill—still in draft form — proposed by Senator Graham in February 2010, would establish a clean energy standard (CES) that operates like a national combined efficiency and renewable electricity standard (CERES), but allows nuclear, advanced coal, and newly retired power plants with carbon-intensive emissions to qualify for the clean electricity target calculation. In theory, Senator Graham's bill also could operate within a larger cap-and-trade scheme, although it is more likely to be considered as part of an energy-only set of provisions should the 111 th Congress not pass major climate legislation.

At the state and regional level, 29 states and the District of Columbia had RPS legislation as of December 2009, and regional programs are emerging to cap carbon dioxide $\left(\mathrm{CO}_{2}\right)$ emissions. The Regional Greenhouse Gas Initiative (RGGI) established a carbon cap-and-trade system in 10 northeastern and mid-Atlantic states to reduce carbon-dioxide emissions from the power sector by $10 \%$ below the 2009 level by 2018. Two other regional systems - the Western Climate Initiative (WCI) and the Midwest Greenhouse Gas Reduction Accord - are being developed with their own cap-and-trade systems. Given the existing state RPS standards and emerging federal RPS and carbon cap-and-trade systems, questions have arisen about the impact these policies could have on the immediate and long-term development of renewable energy markets.

This report examines the impact of various RPS and cap-and-trade policy options on the U.S. electricity sector, focusing mainly on renewable energy generation. The analysis uses NREL's Regional Energy Deployment System (ReEDS) model to examine the impact of an emissions cap, similar to that proposed in the Waxman-Markey bill, as well as lower and higher cap scenarios. It also examines the effects of combining various RPS targets with the emissions caps. The generation mix, carbon emissions, and electricity price are examined for various policy combinations to simulate the effect of implementing policies simultaneously.

This analysis also examines implementation issues stemming from the simultaneous operation of an RPS and a carbon cap-and-trade system, such as the overlap of renewable energy certificate (REC) and carbon markets, and the treatment of REC imports under regional cap-and-trade programs. The RGGI and the European Union's Emissions Trading Scheme provide limited experience with these overlapping policies, and experience in these regions is briefly examined. Policy design details can vary, however, and the specific design determines the level of interaction and impact of simultaneously implementing future RPS and carbon-emissions caps.

1. The RPS provisions included in the Waxman-Markey and Bingaman bills are combined renewable energy and energyefficiency standards; this allows the targets to be met with renewable energy or energy efficiency (up to an established limit). The RPS scenarios examined here have targets that only can be met with renewable energy. Energy-efficiency provisions are treated separately. 


\section{Methodology}

This analysis relies on NREL's ReEDS model that simulates the least-cost expansion of electricity generation capacity and transmission in the United States. The model is used here to simulate the electricity generation mix under various policy scenarios, including carbon cap and RPS levels (see text box below). The text box below describes how ReEDS functions. ${ }^{2}$ To determine the interaction between federal carbon cap-and-trade policies and a federal RPS, 12 scenarios were modeled. The scenarios, listed in Table 1, model cap-and-trade policies with different cap and RPS levels. The effect of load reduction attributable to energy-efficiency provisions in the Waxman-Markey bill is also captured in the RPS and cap scenarios as an input to the model, except where noted.

\section{Overview of the Regional Energy Deployment System Model}

The National Renewable Energy Laboratory developed the Regional Energy Deployment System (ReEDS) model to analyze energy and climate policy options in the U.S. electricity sector. ReEDS is a linear programming model that simulates the least-cost expansion of electricity generation capacity and transmission, with detailed treatment of renewable electric options. ReEDS minimizes the system-wide cost of meeting forecasted electric loads, reserve requirements, and emission constraints by building and operating new generators and transmission in 22 two-year increments spanning from 2006 to 2050.

ReEDS is unique in its ability to simulate access to and cost of transmission, access to and quality of renewable resources, the variability of wind and solar power, and the impact of variability on the reliability of the grid. ReEDS addresses these issues through a highly discretized regional structure (356 resource areas), explicit accounting for the variability in wind and solar output over time, and consideration of ancillary services requirements and costs.

ReEDS simulates "feedback" effects in the electricity market resulting from changes in demand, including how greater or lesser use of renewables might impact the price of fossil fuels used in power generation.

This analysis examined RPS scenarios with renewable energy targets of $15 \%, 20 \%$, and $25 \%$ of electricity sales by 2020.The RPS scenarios considered here are more stringent than comparable nominal targets in recently proposed legislation, because recently proposed bills have exclusions (e.g., exempting small utilities from the requirement, allowing efficiency to substitute for renewables to meet targets) that reduce the effective renewable-energy targets considerably. For example, the $15 \%$ RPS modeled here is similar to - but considerably more stringent than - the Bingaman bill's (American Clean Energy Leadership Act of 2009, S. 1462) 15\% combined efficiency and renewable energy standard. The scenario modeled here applies to all utilities, and the entire target must be met with renewable energy; no efficiency substitution is allowed. ${ }^{3}$ The

2. For additional information on the ReEDS model, see http://www.nrel.gov/analysis/reeds/background.html (accessed May11, 2010).

3. The interim targets for the 15\% RPS scenario modeled here are derived from those in the Bingaman bill in the Senate. However, the RPS targets modeled here are considerably more stringent than the Bingaman bill target, because the bill allows $27 \%$ of the targets to be met with efficiency and exempts utilities with less than 4 TWh of sales, bringing the effective peak RPS target to $7.5 \%$ (rather than the nominal 15\%). The 15\% RPS scenario modeled here assumes that efficiency measures are separate from the RPS. 
$15 \%$ RPS modeled also is similar to the renewable energy targets in the Waxman-Markey bill (after accounting for efficiency substitution allowed in the bill) except for some differences in interim targets and other exclusions in the bill. ${ }^{4}$

The $15 \%$ RPS scenario modeled here remains fixed at $15 \%$ after 2020 ; the $20 \%$ and $25 \%$ RPS scenarios modeled continue to increase $1 \%$ annually through 2030 , with final renewable energy targets of $30 \%$ and $35 \%$ respectively. ${ }^{5}$ The RPS scenarios were modeled with various cap levels to determine whether, and at what level, a RPS could drive renewable energy generation independently. The assumptions of the alternative RPS scenarios are summarized in Table 1.

All of the RPS scenarios examined here include a load-reduction component from energy savings because most of the recent federal RPS legislative proposals also include substantial energy-efficiency provisions. These levels of efficiency might not be achieved, however, without specific policy requirements.

- Load reduction assumed in the scenarios in this analysis is based on estimates of load reduction from provisions of the Waxman-Markey bill related to building codes, allowance allocations for energy efficiency programs, and other energy savings estimated to be driven by the bill. The load reduction is assumed to be $8 \%$ in 2020 and 5\% in 2030 . The assumptions for this input are derived from EPA's analysis of the Waxman-Markey bill (EPA 2009). ${ }^{6}$ All of the RPS and cap scenarios analyzed here include the same loadreduction assumptions, with the exception of the reference case and cap-only scenario (where it is noted).

- The cost of implementing energy-efficiency measures is not taken into account in the electricity price calculations, thus underestimating electricity price impacts to some degree. In many instances, however, the cost of the energy savings would not be undertaken by utilities (e.g., for building codes or appliance standards), and therefore would not be reflected in electricity prices.

Alternative cap scenarios also were developed (see Table 1). To model the effects of a cap-andtrade program on the electricity sector in ReEDS, it is necessary to exogenously input a cap into the model to reflect the level of emissions achieved by the electricity sector exclusively. This study uses the projected level of emissions through 2050 from EPA's analysis of the Waxman-Markey bill, which reflects the use of domestic and international offsets, banking, and borrowing of allowances. The EPA's results are obtained from its ADAGE and IGEM models (EPA 2009). ${ }^{7}$

\footnotetext{
4. The 15\% RPS target modeled here is similar to the Waxman-Markey bill assuming that obligated entities would achieve onequarter of the bill's 20\% RPS target through efficiency, as the bill allows. The interim targets of the $15 \%$ RPS modeled, however, are based on the Bingaman bill targets, which are less stringent than those of the Waxman-Markey bill. Conversely, the RPS modeled here is more stringent than the Waxman-Markey bill because it does not exclude small utilities that serve loads less than 4 million MWh. The effective target of the Waxman-Markey bill RPS drops to $12.5 \%$ accounting for the small utility exemption and $25 \%$ efficiency substitution. The bill also allows states to petition to have $40 \%$ of the RPS target be met with efficiency each year, which would further reduce the effective target, if implemented. The scenarios modeled here do not account for any of these exemptions or substitutions.

5. The interim targets for these two scenarios are based on the Waxman-Markey targets and are more aggressive than those in the Bingaman bill and in the $15 \%$ RPS modeled here.

6. Slide 36, EPA's Analysis of H.R. 2454-Appendix: http://www.epa.gov/climatechange/economics/pdfs/ HR2454_Analysis_Appendix.pdf (accessed May 11, 2010).

7. See the EPA's Climate Economics Web site for more information on its modeling results: http://www.epa.gov/ climatechange/economics/economicanalyses.html (accessed May 11, 2010).
} 
The base cap considered in the analysis is a $17 \%$ reduction of 2005 GHG emissions by 2020 , and $42 \%$ reduction of 2005 GHG emissions by 2030 with offsets and banking, consistent with the Waxman-Markey bill passed by the House in June 2009. In addition, high and low caps were evaluated. In this analysis "low cap" refers to a cap that is $20 \%$ less restrictive, ${ }^{8}$ - it allows more carbon to be emitted - than the Waxman-Markey cap. Conversely, a "high cap" refers to a cap that is $20 \%$ more restrictive, allowing less carbon to be emitted than the Waxman-Markey cap. Both scenarios modified EPA's projections of the allowed level of carbon dioxide under the cap.

Table 1. Description of the Scenarios

\begin{tabular}{|c|c|}
\hline Scenario Name & Scenario Description \\
\hline Reference & $\begin{array}{l}\text { The reference case reflects the existing policy environment but includes regulatory risk through a } 3 \% \\
\text { increase in the interest rate for financing coal-fired power plants (taken from the AEO 2009). }\end{array}$ \\
\hline $15 \%$ RPS & $\begin{array}{l}15 \% \text { RPS by } 2020 \text { with interim targets of } 3 \% \text { by } 2011,8 \% \text { by } 2016 \text {, and } 15 \% \text { by } 2020 \text {, remaining } \\
\text { constant through } 2030 \text {. Load reduced to reflect efficiency provisions in H.R. } 2454 \text {. }\end{array}$ \\
\hline $20 \%$ RPS & $\begin{array}{l}20 \% \text { RPS by } 2020 \text { with interim targets of } 6 \% \text { by } 2012,13 \% \text { by } 2016,20 \% \text { by } 2020 \text {, and increasing } 1 \% \\
\text { annually to } 30 \% \text { by } 2030 \text {. Load reduced to reflect efficiency provisions in H.R. } 2454 \text {. }\end{array}$ \\
\hline $25 \%$ RPS & $\begin{array}{l}25 \% \text { RPS by } 2020 \text { with interim targets of } 6 \% \text { by } 2012,15 \% \text { by } 2016,25 \% \text { by } 2020 \text {, and increasing } 1 \% \\
\text { annually to } 35 \% \text { by } 2030 \text {. Load reduced to reflect efficiency provisions in H.R. } 2454 \text {. }\end{array}$ \\
\hline Cap or Base Cap & $\begin{array}{l}\text { A } 17 \% \text { reduction in } 2005 \text { GHG emissions by } 2020 \text {, and } 42 \% \text { reduction by } 2030 \text { with offsets and banking. } \\
\text { Interim targets require } 3 \% \text { reduction of } 2005 \text { GHG emissions by } 2012 \text {, and an ultimate reduction of } 83 \% \\
\text { reduction by } 2050 \text {. }\end{array}$ \\
\hline Low Cap & $\begin{array}{l}\text { A cap } 20 \% \text { less stringent than the base cap (i.e., allowable emissions are } 20 \% \text { greater than in the base } \\
\text { cap case). }\end{array}$ \\
\hline High Cap & $\begin{array}{l}\text { A cap } 20 \% \text { more stringent than the base cap (i.e., allowable emissions are } 20 \% \text { less than in the base } \\
\text { cap case). }\end{array}$ \\
\hline
\end{tabular}

There are other assumptions made that are not specific to this analysis but can significantly affect the results and are therefore worth mentioning. These include the following:

- Technology cost and performance parameters and projections primarily are from Black and Veatch as estimated for the 20\% Wind Energy by 2030 study (DOE 2008) (see Figure 1). Thus, recent escalation in capital costs is not captured, although relative costs across technologies have the greatest impact on results. The costs for carbon capture and sequestration do not include incentives proposed in recent legislation.

- Fuel cost projections are from the Energy Information Administration (EIA) Annual Energy Outlook (AEO) 2009 reference case, April edition (American Recovery and Reinvestment Act, EIA 2009a). The EIA fuel-cost projections are used for the initial price trajectory of natural gas; however, the actual prices used in the model are calculated based on natural gas consumption and the short- and long-term elasticity of demand for natural gas. The price of natural gas, in particular, can have a great impact on both investment and dispatch decisions in the model.

- To reflect existing policy incentives, wind and other qualifying renewable electricity generators receive a production tax credit (PTC) of 2.1 cents per kilowatt-hour (in 2008\$) through 2012; qualifying non-wind renewable generation receives the credit through 2013. Concentrating solar power (CSP) and solar photovoltaics (PV) receive an investment tax credit (ITC) of $30 \%$ through 2016 , after which the ITC drops to $10 \%$.

8. Thus, the emissions targets are $20 \%$ less than the $17 \%$ reductions in 2020 assumed in the base case, meaning required reductions are $13.6 \%$. 
- Nuclear capital costs were determined by multiplying the Black and Veatch projections by 1.5 (from roughly $\$ 3,000 / \mathrm{kW}$ to $\$ 4,500 / \mathrm{kW}$ ) to better represent recently publicized cost-estimate increases and the current social-political climate of uncertainty regarding the technology.

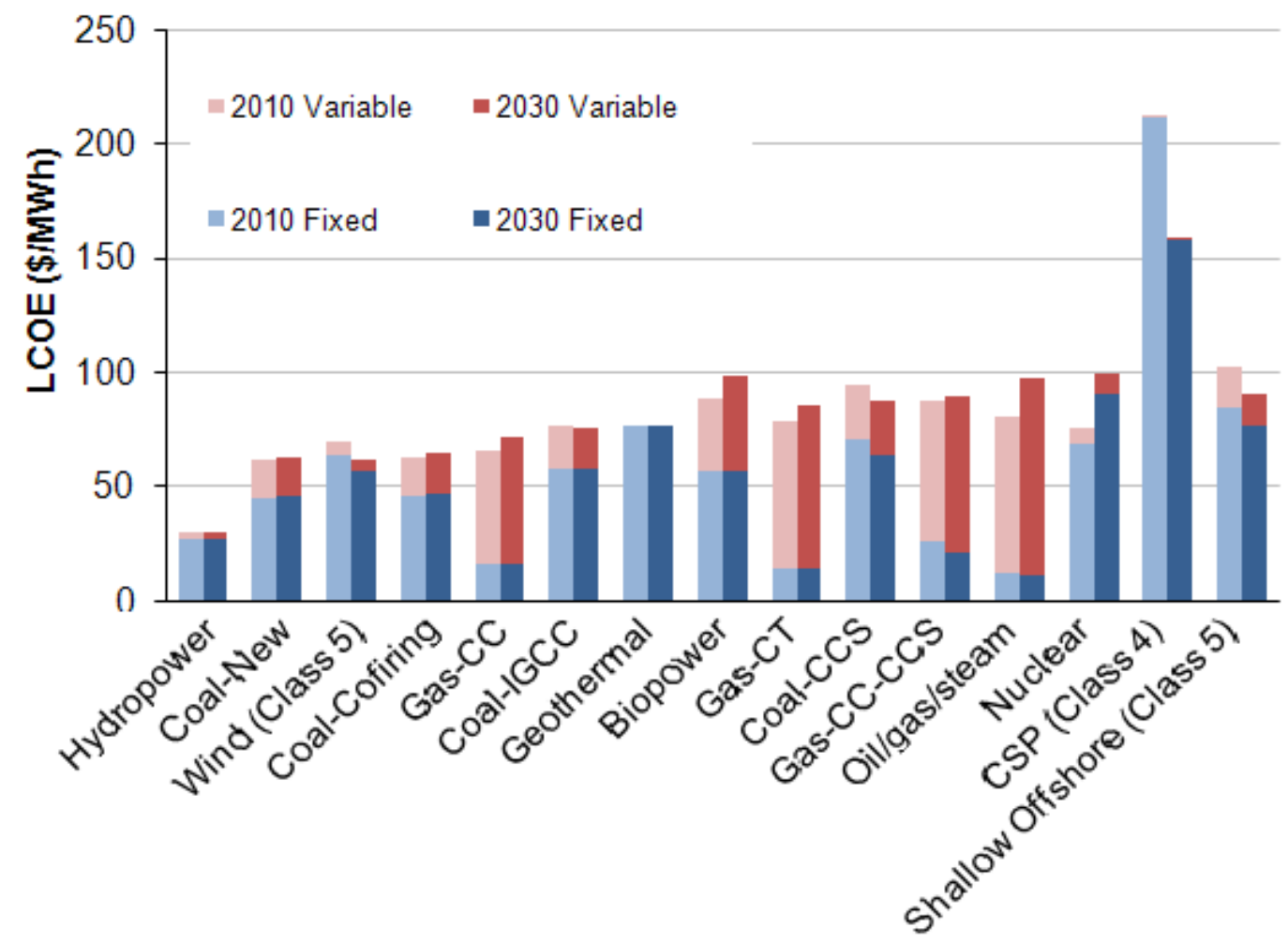

Figure 1. Levelized cost of electricity inputs used in ReEDS

- Load growth rates through 2030 are defined by the North American Electric Reliability Corporation (NERC) region/sub-region from the EIA AEO 2009 reference case (EIA 2009a). From 2031 through 2050 the data is obtained using linear extrapolation of the AEO load from 2020 to 2030.

- All existing state-level RPS targets with enforceable penalties are met in the baseline case. Most state RPS programs ramp-up renewable requirements through 2020 or 2025 before leveling off. State RPS targets are obtained from the Database of State Incentives for Renewables and Efficiency (DSIRE). ${ }^{9}$ Interstate REC trading allowed under current state RPS policies is not captured in the analysis.

- The analysis explicitly accounts for the cost of new transmission for all power generation options by determining when new transmission lines are needed and including the cost of building them.

9. For additional information, see DSIRE database at http://www.dsireusa.org/ (accessed May 10, 2010). 
- New carbon capture and sequestration (CCS), new nuclear, and hydro are excluded from the total generation to which the RPS constraint is applied consistent with recent legislative proposals.

- Distributed PV counts as triple credit towards meeting the RPS.

- Coal-based technologies have their interest rate increased by $3 \%$ to reflect the risk of having to address carbon emissions.

Although ReEDs can model policy features such as carbon dioxide reduction, renewable energy capacity and generation, and electricity price, many policy benefits are not modeled. For example, ReEDs does not model job creation or economic development, which concern many governments that are implementing renewable energy or carbon policies.

\section{Modeling Results}

The results of our analysis comparing various carbon dioxide emission cap and RPS policy levels are presented below. In each case, we focus on the generation mix, electricity price, and carbon emissions level - the outputs of the ReEDs model. First, we compare RPS and carbon cap scenarios both individually and combined. Then we examine the effect of varying the cap levels while holding the RPS constant. Finally, we evaluate varying the RPS levels, holding the carbon cap steady to see the effect on generation mix and cost.

\section{Emissions Cap and Renewable Portfolio Standards-Individually and Combined}

The reference case is compared with four other scenarios - the base cap alone (with no load reduction), two RPS levels (15\% and 25\%), and a 15\% RPS with the base cap.

\section{Generation Impacts}

Figure 2 and Table 2 present the electricity generation mix in 2020 and 2030 for the reference case, the two cap scenarios, and the two RPS scenarios. Because the reference case and base cap alone do not assume any load reduction from efficiency provisions, the total generation needed to meet the load is greater. This explains why the base cap alone results in more renewable generation than the base cap with 15\% RPS (see Table 2). Appendix A presents generation results for all technologies modeled.

- The cap cases drive significant renewable generation, particularly in the 2030 timeframe. Adding a cap to the $15 \%$ RPS case more than doubles the non-hydro renewable generation in 2030. Wind power makes the greatest contribution to this increase, and CSP, geothermal, and biopower also make significant contributions. The $15 \%$ RPS case without a cap has only a modest effect on the generation mix from the reference case in 2030. Although the more stringent $25 \%$ RPS case drives a significant amount of new renewable generation as compared to the reference case, it still drives less renewable generation in 2030 than the cap scenarios and has substantially more coal.

- In the near term (2020), a 25\% RPS drives greater renewable generation than in the cap cases. In the 2020 timeframe, the 25\% RPS case results in 864 TWh of renewable energy generation which is slightly higher than the $800 \mathrm{TWh}$ in the cap-only case (no load reduction) and significantly more renewables than the 594 TWh in the case of the cap with 15\% RPS. Again, the cap-only case results in more renewable generation than the 
cap with an RPS because no efficiency provisions are assumed and the load to which the cap is applied is higher. When the cap is applied to the lower load level (i.e., the loadreduction assumption is the same as in the RPS cases), the amount of renewable generation is the same as in the 15\% RPS with cap case, as the cap supports more renewable energy generation than the RPS. Thus, the cap applied to reduced loads drives about 100 TWh or $20 \%$ more non-hydro renewable generation in 2020 than the $15 \%$ RPS alone (with no cap). The RPS cases result in less natural gas and more coal in the generation mix than in the cap cases; the latter effect becomes more pronounced over time. Also, adding the $15 \%$ RPS and load reduction to a cap results in a slightly larger amount of coal generation (2-5\%) because the emissions benefit of load reduction enables more coal to operate and still meet the cap.

- The cap cases result in significant reduction in coal generation and a shift from coal to gas in the short term. As might be expected, the cap cases have significantly less coal generation in the 2030 timeframe than do the RPS scenarios (no-cap) and reference scenario. In the reference case, coal generation accounts for $50 \%$ of the total generation and in the 15\% RPS with cap case it accounts for half that amount. By 2030, CCS technologies do not contribute to the generation mix because they are not costcompetitive in that time frame in the analysis. In 2020, the cap causes a shift from coal to natural gas generation, but by 2030, the cap cases have similar amounts of natural gas generation as in the reference case, with a greater shift to renewable generation.

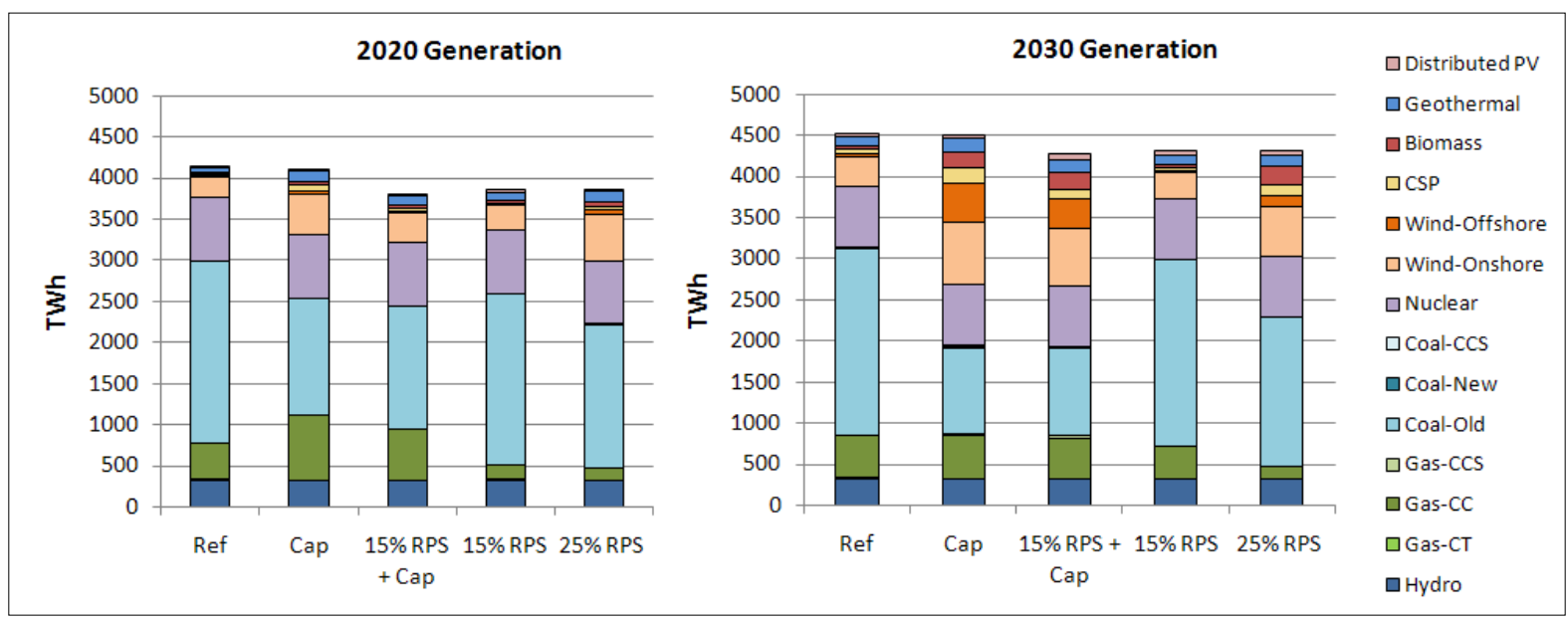

Figure 2. Electric generation mix with RPS and cap, individually and combined in 2020 and 2030 
Table 2. Electric Generation Mix with RPS and Cap, Individually and Combined by Scenario and Year

\begin{tabular}{|c|c|c|c|c|c|c|c|c|c|c|}
\hline & \multicolumn{2}{|c|}{ Reference } & \multicolumn{2}{|l|}{ Cap } & \multicolumn{2}{|c|}{ 15\% RPS + Cap } & \multicolumn{2}{|c|}{$15 \%$ RPS } & \multicolumn{2}{|c|}{$25 \%$ RPS } \\
\hline & $\begin{array}{l}\text { Generation } \\
\text { (TWh) }\end{array}$ & $\%^{*}$ & $\begin{array}{l}\text { Generation } \\
\text { (TWh) }\end{array}$ & $\%^{*}$ & $\begin{array}{l}\text { Generation } \\
\text { (TWh) }\end{array}$ & $\%^{*}$ & $\begin{array}{l}\text { Generation } \\
\text { (TWh) }\end{array}$ & $\%^{*}$ & $\begin{array}{l}\text { Generation } \\
\text { (TWh) }\end{array}$ & \%* \\
\hline \multicolumn{11}{|c|}{2020} \\
\hline Gas & 459 & $11 \%$ & 801 & $19 \%$ & 638 & $17 \%$ & 201 & $5 \%$ & 167 & $4 \%$ \\
\hline Coal & 2,226 & $54 \%$ & 1,419 & $35 \%$ & 1,487 & $39 \%$ & 2,075 & $54 \%$ & 1,744 & $45 \%$ \\
\hline $\begin{array}{l}\text { Non-Hydro } \\
\text { Renewables }\end{array}$ & 366 & $9 \%$ & 800 & $19 \%$ & 594 & $16 \%$ & 490 & $13 \%$ & 864 & $22 \%$ \\
\hline $\begin{array}{l}\text { Total } \\
\text { Generation** }\end{array}$ & 4,137 & & 4,106 & & 3,805 & & 3,852 & & 3,862 & \\
\hline \multicolumn{11}{|c|}{2030} \\
\hline Gas & 547 & $12 \%$ & 535 & $12 \%$ & 496 & $12 \%$ & 412 & $10 \%$ & 157 & $4 \%$ \\
\hline Coal & 2,273 & $50 \%$ & 1,047 & $23 \%$ & 1,066 & $25 \%$ & 2,261 & $52 \%$ & 1,821 & $42 \%$ \\
\hline $\begin{array}{l}\text { Non-Hydro } \\
\text { Renewables }\end{array}$ & 649 & $14 \%$ & 1,813 & $40 \%$ & 1,606 & $38 \%$ & 592 & $14 \%$ & 1,289 & $30 \%$ \\
\hline $\begin{array}{l}\text { Total } \\
\text { Generation** }\end{array}$ & 4,522 & & 4,502 & & 4,274 & & 4,319 & & 4,320 & \\
\hline
\end{tabular}

\section{Carbon Emission Reductions}

The cap cases result in the greatest carbon dioxide emissions reductions over the 2030 timeframe, and the RPS scenarios (with no cap) result in significant reductions in the 2020 timeframe as compared to the reference case. The load reduction assumed from the efficiency provisions considered in the RPS scenarios is responsible for part of the emissions reductions. Figure 3 illustrates that the cap cases result in nearly a 50\% reduction in emissions in 2030 compared to the reference case. Note that the two cap cases overlap in Figure 3, because the cap sets the emissions at the same level in both cases.

The 25\% RPS case achieves emission levels similar to cap cases through 2020, suggesting that an aggressive RPS target could place the power sector on track to meet carbon dioxide emissions reductions goals similar to the cap scenario over the next decade or so. An RPS, however, does not provide a carbon price signal that would influence longer-term technology choice and investment decisions on a carbon-emissions basis, nor does it provide as much certainty in achieving emissions reductions particularly if demand increases. As shown in Figure 2, an RPS has significantly less impact on the generation mix of coal and natural gas than does an emissions cap. After 2020, the emissions levels diverge, as the cap cases become more stringent and reduce the coal generation compared to the RPS-only cases. In the $15 \%$ RPS cases, the carbon dioxide emissions increase in the post-2020 timeframe largely because the RPS is held constant at $15 \%$ after 2020 . In the $25 \%$ RPS case, the RPS target continues to climb to $35 \%$ by 2030; emissions rise in the later years as a result of increases in fossil generation required to meet loads. Load reduction from efficiency measures in the RPS scenarios is assumed to be $8 \%$ in 2020 , declining to $5 \%$ in 2030 . 


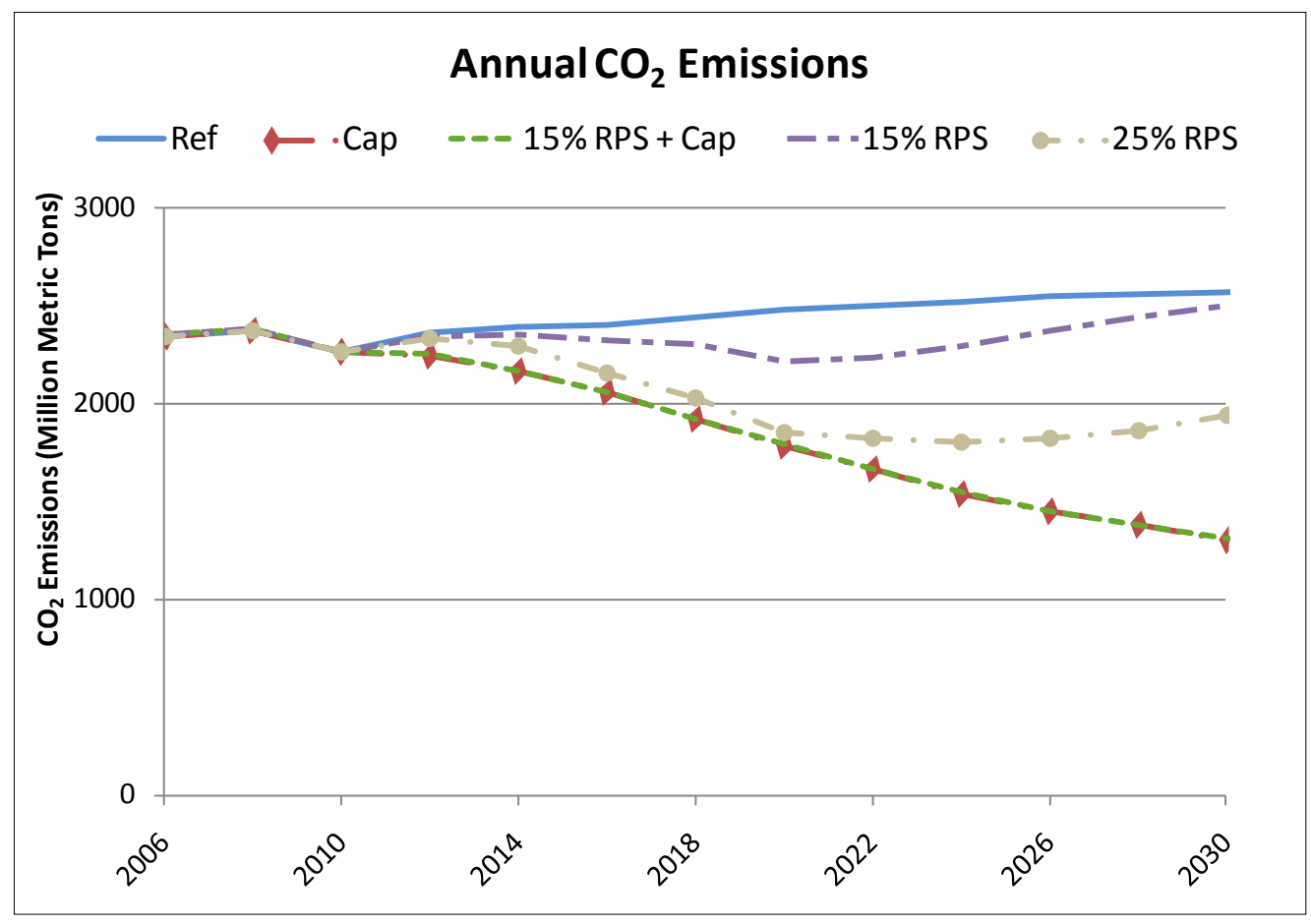

Figure 3. Carbon dioxide emissions levels for cap and RPS scenarios

\section{Electricity Price Impacts}

Figure 4 shows the average national retail electricity price through 2030. In general, the cap and RPS scenarios do not result in substantial increases in electricity price. Although these policies require greater investment in technologies with higher capital cost, fuel costs are reduced, offsetting the impact on average power price. Also, the decrease in the demand for coal in cap scenarios causes a reduction in coal prices, which further reduces the electricity price.

The cap cases (cap and the 15\% RPS with cap) lead to larger-although still modest-increases in electricity prices, as they achieve the greatest reduction in carbon emissions. The electricity price in the $15 \%$ RPS with cap case is $7 \%$ more than the reference case electricity price in 2030 , and the cap-alone case results in a 9\% increase from the reference case. The cost savings are due to the load reduction assumptions; the cap with efficiency case has the same electricity price as the $15 \%$ RPS with cap case. The electricity price for the $15 \%$ RPS (no cap) case is $3 \%$ less than for the reference case in 2030, largely as a result of energy savings. The electricity price for the $25 \%$ RPS is $2 \%$ below the reference case in part because of natural gas savings. All of the RPS cases include an assumption that load is reduced by energy savings achieved through complementary efficiency measures. The cost of these reductions is not captured in the analysis and some measures - such as appliance standards and building codes - would not increase electricity prices. The analysis also does not capture the benefits of efficiency measures in the form of reduced consumer bills. 


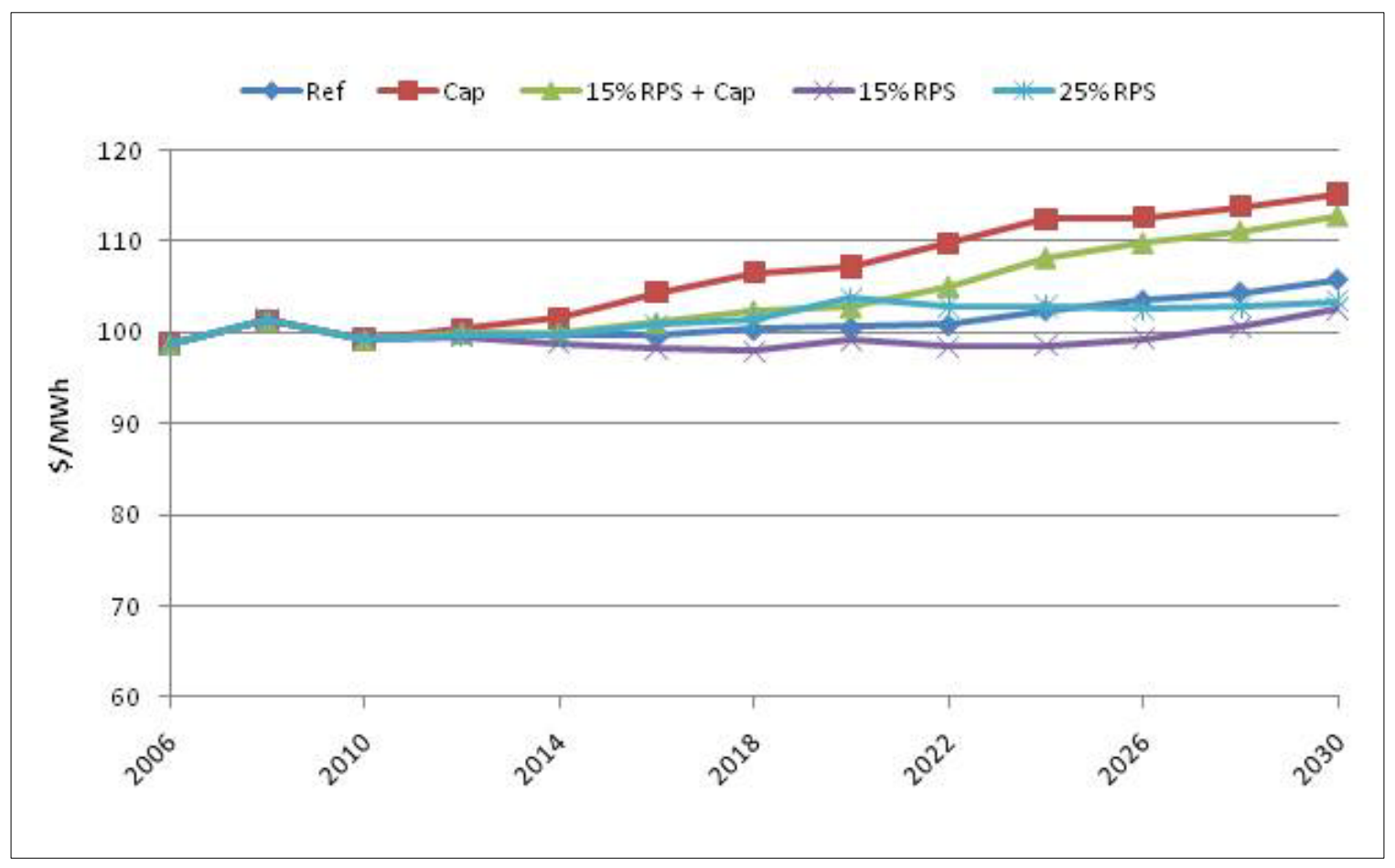

Figure 4. National average electricity price for cap and RPS scenarios (\$2009)

\section{Effect of Varying Carbon Cap Levels}

We also examined the effect of lower and higher carbon caps combined with various levels of RPS. As described above, the low and high emissions cap scenarios are $20 \%$ lower (20\% less stringent) and $20 \%$ higher (20\% more stringent) than the cap scenario in the analysis. The base cap is modeled after the Waxman-Markey bill, which calls for a 17\% reduction in 2005 greenhouse gas emissions by 2020, and a 42\% reduction by 2030 .

\section{Generation Impacts}

Figure 5 and Table 3 present the generation mix resulting from a low cap, base cap, and high cap combined with a $25 \%$ RPS. All three cap cases show essentially the same amount of renewable energy in 2020. In the low and base cap cases, the RPS target is driving the renewable energy generation in 2020, while the cap drives it under the high-cap case. Thus, if the goal is to achieve greater renewable energy penetration levels, an RPS could be more important to include under modest cap scenarios in the near term. Appendix A presents tables summarizing generation results for all technologies modeled.

In 2030, the generation mix is driven by the cap in all scenarios. The high cap leads to investments in natural gas over coal. This effect also is seen in the near term under the high cap case. In 2020, natural gas constitutes $17 \%$ of the total generation in the high cap case and only $4 \%$ in the low cap case. The total generation also decreases in more stringent cap cases because the ReEDs model addresses demand elasticity (i.e., as the electricity price increases due to a higher cap, the demand for energy declines). This explains why there is less renewable generation in the high-cap case than in the base cap for 2030. 


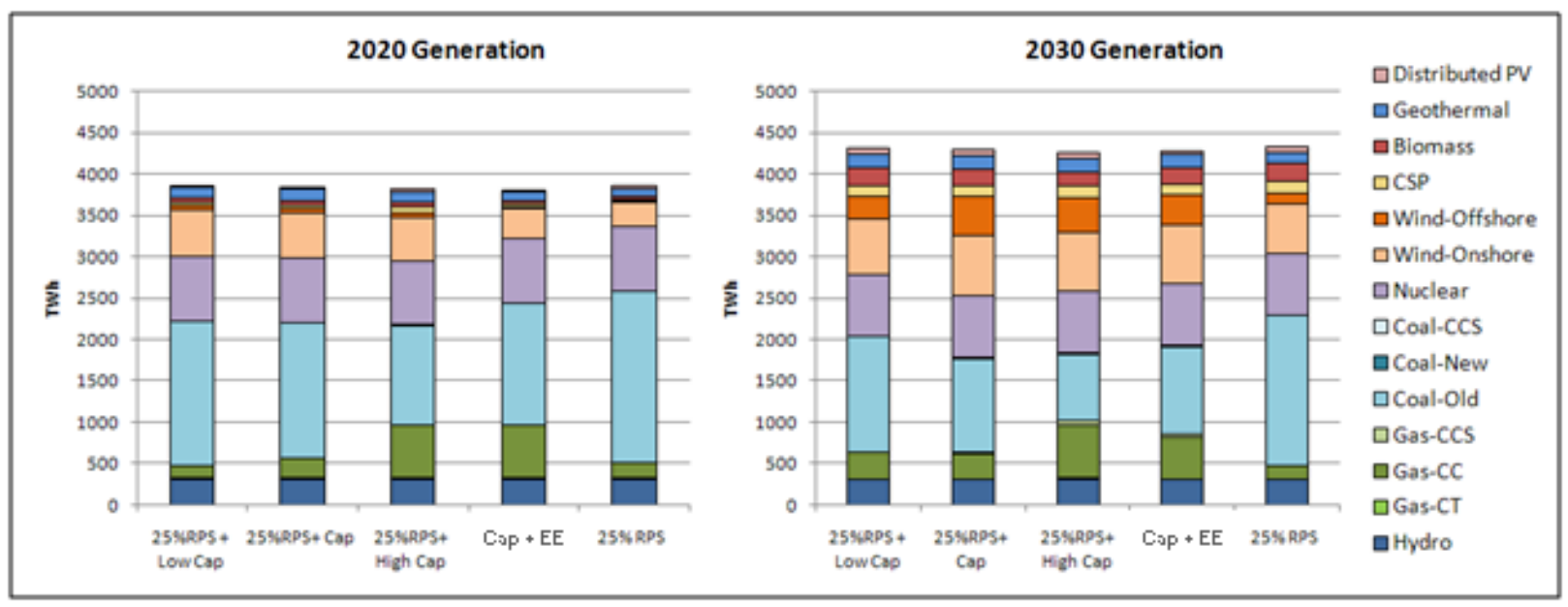

Figure 5. Generation mix resulting from low- and high-cap scenarios with $25 \%$ RPS

Table 3. Generation Mix by Cap Level and Year

\begin{tabular}{|c|c|c|c|c|c|c|c|c|}
\hline & \multicolumn{2}{|c|}{ Reference } & \multicolumn{2}{|c|}{ 25\%RPS + Low Cap } & \multicolumn{2}{|c|}{$25 \%$ RPS + Cap } & \multicolumn{2}{|c|}{ 25\%RPS + High Cap } \\
\hline & $\begin{array}{l}\text { Generation } \\
\text { (TWh) }\end{array}$ & $\% *$ & $\begin{array}{l}\text { Generation } \\
\text { (TWh) }\end{array}$ & $\% *$ & $\begin{array}{l}\text { Generation } \\
\text { (TWh) }\end{array}$ & $\% *$ & $\begin{array}{l}\text { Generation } \\
\text { (TWh) }\end{array}$ & \%* \\
\hline \multicolumn{9}{|c|}{2020} \\
\hline Gas & 459 & $11 \%$ & 167 & $4 \%$ & 247 & $6 \%$ & 655 & $17 \%$ \\
\hline Coal & 2,226 & $54 \%$ & 1,748 & $45 \%$ & 1,648 & $43 \%$ & 1,208 & $32 \%$ \\
\hline $\begin{array}{l}\text { Non-Hydro } \\
\text { Renewables }\end{array}$ & 366 & $9 \%$ & 862 & $22 \%$ & 865 & $22 \%$ & 864 & $23 \%$ \\
\hline Total Generation** & 4,137 & & 3,863 & & 3,845 & & 3,813 & \\
\hline \multicolumn{9}{|c|}{2030} \\
\hline Gas & 547 & $12 \%$ & 321 & $7 \%$ & 302 & $7 \%$ & 655 & $15 \%$ \\
\hline Coal & 2,273 & $50 \%$ & 1,398 & $32 \%$ & 1,148 & $27 \%$ & 799 & $19 \%$ \\
\hline $\begin{array}{l}\text { Non-Hydro } \\
\text { Renewables } \\
\end{array}$ & 649 & $14 \%$ & 1,529 & $36 \%$ & 1,759 & $41 \%$ & 1,671 & $39 \%$ \\
\hline Total Generation** & 4,522 & & 4,304 & & 4,289 & & 4,254 & \\
\hline
\end{tabular}




\section{Electricity Price Impacts, Carbon Dioxide, and Renewable Energy Credit Prices}

Figure 6 shows the average national retail electricity price through 2030 for the $25 \%$ RPS combined with varying cap levels. There is little difference in electricity price for the low-cap and base cap scenarios through 2020, because the generation mix is similar and the RPS is driving the renewable generation. They begin to diverge thereafter, however, as the base cap begins to drive greater changes in the electricity mix. The $25 \%$ RPS with high cap case results in modestly greater electricity prices over most of the period and drives the generation mix. The carbon dioxide emissions levels are not shown here, as they are driven by the caps and are simply at the level of the base cap and then $20 \%$ greater and $20 \%$ lower for the sensitivity cases.

As shown in Table 4, our analysis generally shows a reduction in carbon dioxide allowance prices in the electric sector when an RPS and load-reduction measures are added to a cap. ${ }^{10}$ Although total costs are not reduced, the modeled efficiency provisions and the RPS (when it drives more renewable generation than the cap) take on a portion of the carbon-reduction burden and associated cost. When an RPS is present, RPS compliance costs are reflected in the REC price. The model yields REC prices of zero when the cap drives more renewable generation than required by the RPS, as in the case of the $15 \%$ RPS with cap. The cap alone case yields a 2020 carbon price of $\$ 52 /$ ton compared to $\$ 25 /$ ton under the $25 \%$ RPS plus cap scenario. The $25 \%$ RPS with cap scenario also yields a \$42/MWh REC price in 2020.

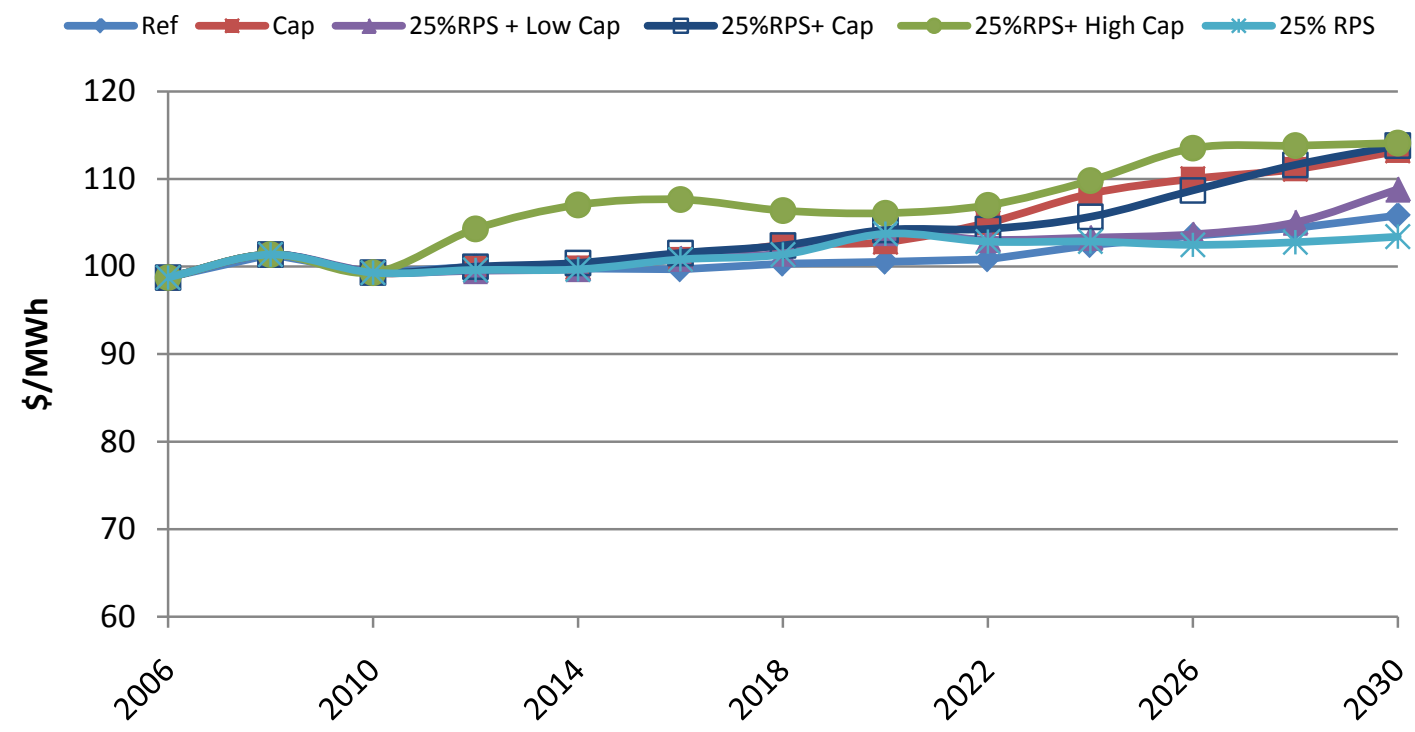

Figure 6. Electricity prices resulting from a $25 \%$ RPS with varying cap levels (2009\$)

The cap level also can impact the price of RECs used for compliance with a federal RPS. Figure 7 presents the REC prices resulting from a 25\% RPS and with a low cap and a base cap. The REC prices are least under the $25 \%$ RPS and cap scenario, because the cap also is providing incentive for the renewables and some of the cost is shifted to compliance costs for the cap. After

10. Given that ReEDS is an electric-sector model only, these estimates represent the marginal cost of abatement in the electric sector which can be used as a proxy for allowance price. It does not reflect an equilibrium price for allowances in an economywide cap, however, as only the electric sector is modeled. 
2025, the REC prices begin to drop steadily under the low-cap case as the cap begins to drive more renewable energy development. Similarly, under the cap case the estimated REC price in the model falls to zero in 2026 because the cap drives all of the renewable energy. Real-world conditions likely would result in greater REC prices. If an RPS is present, RECs likely would trade at some value because of transaction costs, even if the cap is sufficient to drive the renewable energy generation.

Table 4. Carbon Dioxide and REC Prices for Cap and RPS Scenarios (\$2009)

\begin{tabular}{|l|c|c|c|c|}
\hline \multirow{2}{*}{} & \multicolumn{2}{|c|}{ Carbon Price } & \multicolumn{2}{c|}{ REC Price } \\
\cline { 2 - 5 } & $\mathbf{2 0 2 0}$ & $\mathbf{2 0 3 0}$ & $\mathbf{2 0 2 0}$ & $\mathbf{2 0 3 0}$ \\
\hline Cap & $\$ 52$ & $\$ 75$ & - & - \\
\hline Cap with EE & $\$ 48$ & $\$ 70$ & - & - \\
\hline 15\%RPS Plus Cap & $\$ 48$ & $\$ 70$ & $\$ 0$ & $\$ 0$ \\
\hline 25\%RPS Plus Cap & $\$ 25$ & $\$ 77$ & $\$ 42$ & $\$ 0$ \\
\hline 25\% RPS +Plus Low Cap & $\$ 0$ & $\$ 60$ & $\$ 64$ & $\$ 0$ \\
\hline 25\% RPS Plus High Cap & $\$ 52$ & $\$ 76$ & $\$ 0$ & $\$ 0$ \\
\hline 15\% RPS & - & - & $\$ 31$ & $\$ 0$ \\
\hline 25\% RPS & - & - & $\$ 63$ & $\$ 31$ \\
\hline
\end{tabular}

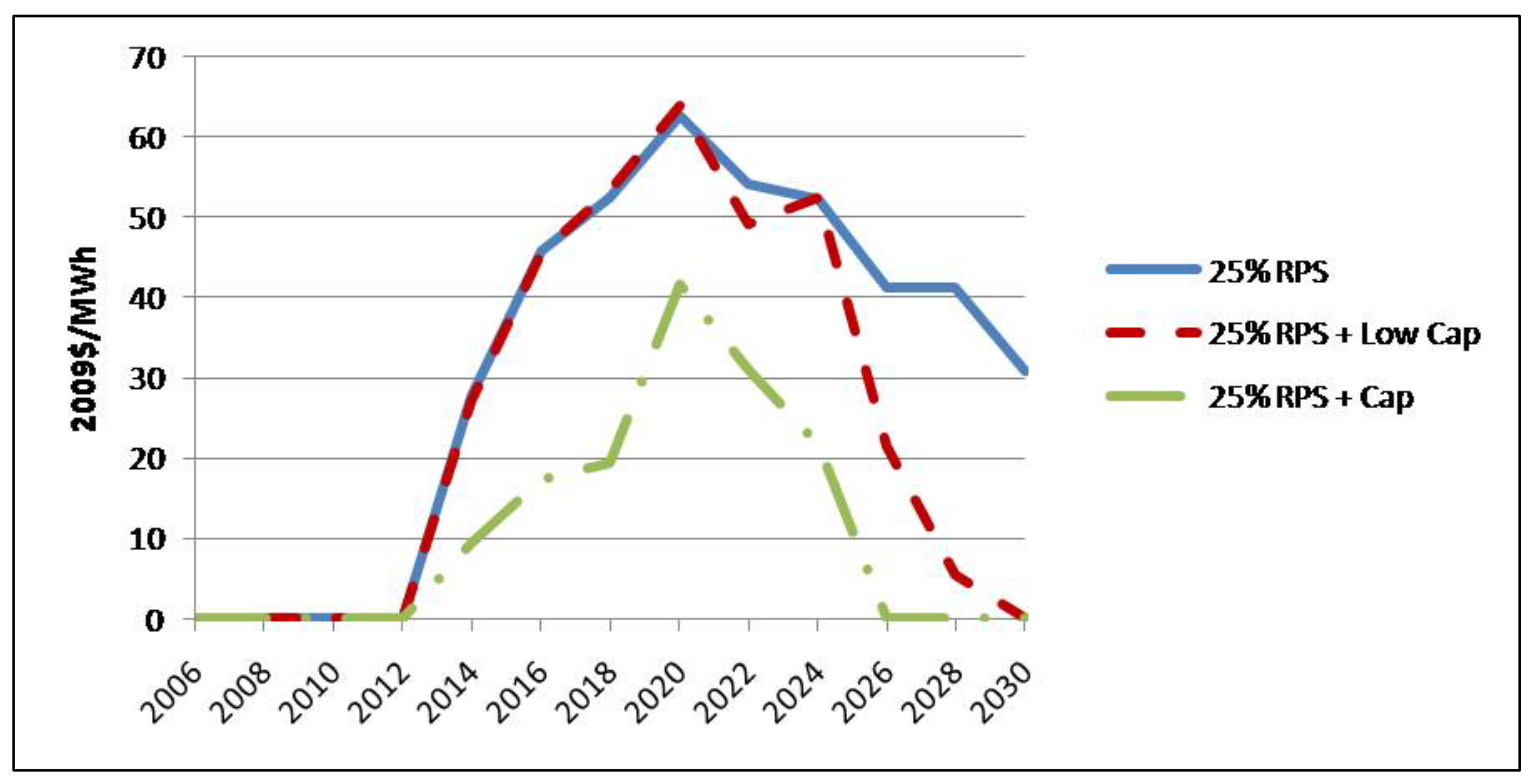

Figure 7. Renewable energy credit prices for $25 \%$ RPS and cap scenarios (2009\$)

\section{Effect of Varying Renewable Portfolio Standard Levels}

We also examined the effect of lower and higher RPS levels combined with an emissions cap. We compare the effect of combining a 15\% RPS, 20\% RPS, or 25\% RPS with the base cap. As described above, the two higher-RPS scenarios increase after 2020 (the 20\% RPS increases to $30 \%$ by 2030 , and the $25 \%$ RPS climbs to $35 \%$ by 2030 ), while the $15 \%$ remains constant after 2020. All of the scenarios include our assumption about reduced load through efficiency measures. 


\section{Generation Impacts}

Figure 8 and Table 5 present results for the three different levels of RPS with the base cap as well as the reference case. In the 2020 timeframe, the RPS drives renewable generation (except in the lowest RPS case). Renewable generation expands to $22 \%$ of the total in 2020 under the $25 \%$ RPS case. ${ }^{11}$ In 2030, when the cap is more stringent, the amount of renewable energy is driven largely by the cap in all cases, although the $25 \%$ RPS and cap case has a slightly more renewable generation. The greater amount of coal generation in the $25 \%$ RPS and cap scenario is a result of the greater emission benefits of the higher penetration of renewable energy driven by the RPS, which allows more coal to operate to meet the cap. Appendix A presents generation results for all technologies modeled.

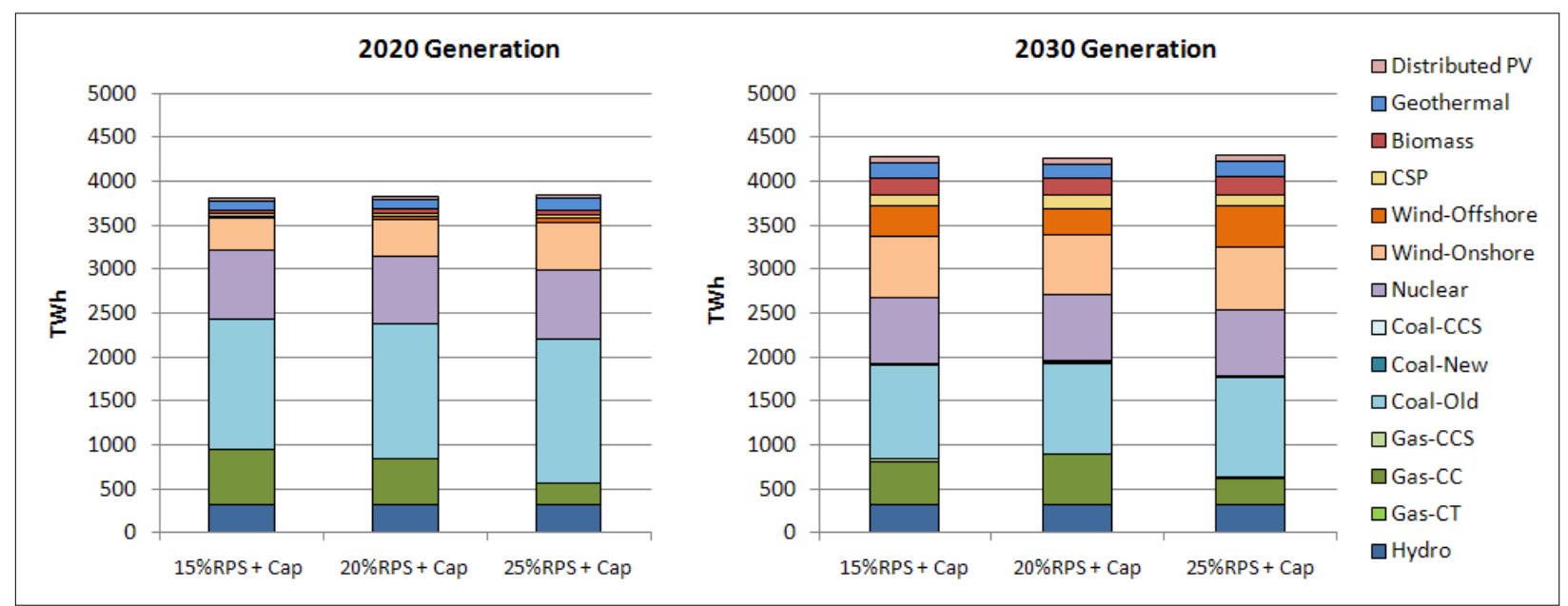

Figure 8. Generation mix resulting from various RPS levels and carbon dioxide cap

Table 5. Generation Mix Resulting by RPS Level with Cap and Year

\begin{tabular}{|c|c|c|c|c|c|c|c|c|}
\hline & \multicolumn{2}{|c|}{ Reference } & \multicolumn{2}{|c|}{ 15\%RPS + Cap } & \multicolumn{2}{|c|}{$20 \%$ RPS + Cap } & \multicolumn{2}{|c|}{$25 \% R P S+$ Cap } \\
\hline & $\begin{array}{c}\text { Generation } \\
\text { (TWh) }\end{array}$ & $\%^{*}$ & $\begin{array}{c}\text { Generation } \\
\text { (TWh) }\end{array}$ & $\%^{*}$ & $\begin{array}{c}\text { Generation } \\
\text { (TWh) }\end{array}$ & $\% *$ & $\begin{array}{c}\text { Generation } \\
\text { (TWh) }\end{array}$ & $\% *$ \\
\hline \multicolumn{9}{|c|}{2020} \\
\hline Gas & 459 & $11 \%$ & 638 & $17 \%$ & 533 & $14 \%$ & 247 & $6 \%$ \\
\hline Coal & 2,226 & $54 \%$ & 1,487 & $39 \%$ & 1,531 & $40 \%$ & 1,648 & $43 \%$ \\
\hline $\begin{array}{l}\text { Non-Hydro } \\
\text { Renewables }\end{array}$ & 366 & $9 \%$ & 594 & $16 \%$ & 672 & $18 \%$ & 865 & $22 \%$ \\
\hline Total Generation** & 4,137 & & 3,805 & & 3,823 & & 3,845 & \\
\hline \multicolumn{9}{|c|}{2030} \\
\hline Gas & 547 & $12 \%$ & 496 & $12 \%$ & 578 & $14 \%$ & 302 & $7 \%$ \\
\hline Coal & 2,273 & $50 \%$ & 1,066 & $25 \%$ & 1,032 & $24 \%$ & 1,148 & $27 \%$ \\
\hline $\begin{array}{l}\text { Non-Hydro } \\
\text { Renewables }\end{array}$ & 649 & $14 \%$ & 1,606 & $38 \%$ & 1,555 & $36 \%$ & 1,759 & $41 \%$ \\
\hline Total Generation** & 4,522 & & 4,274 & & 4,267 & & 4,289 & \\
\hline
\end{tabular}

11. Renewable generation is not equal to the $25 \%$ target because of assumptions that PV receives triple credit and that CCS and hydro are excluded from the estimated total generation to which the RPS target is applied, which is consistent with recent legislative proposals. 


\section{Electricity Price Impacts}

There are relatively small variations in the electricity price resulting from the different RPS levels when combined with a base cap (see Figure 9). The cap largely dictates the electricity price. In each case, the emissions levels are the same and are determined by the cap.

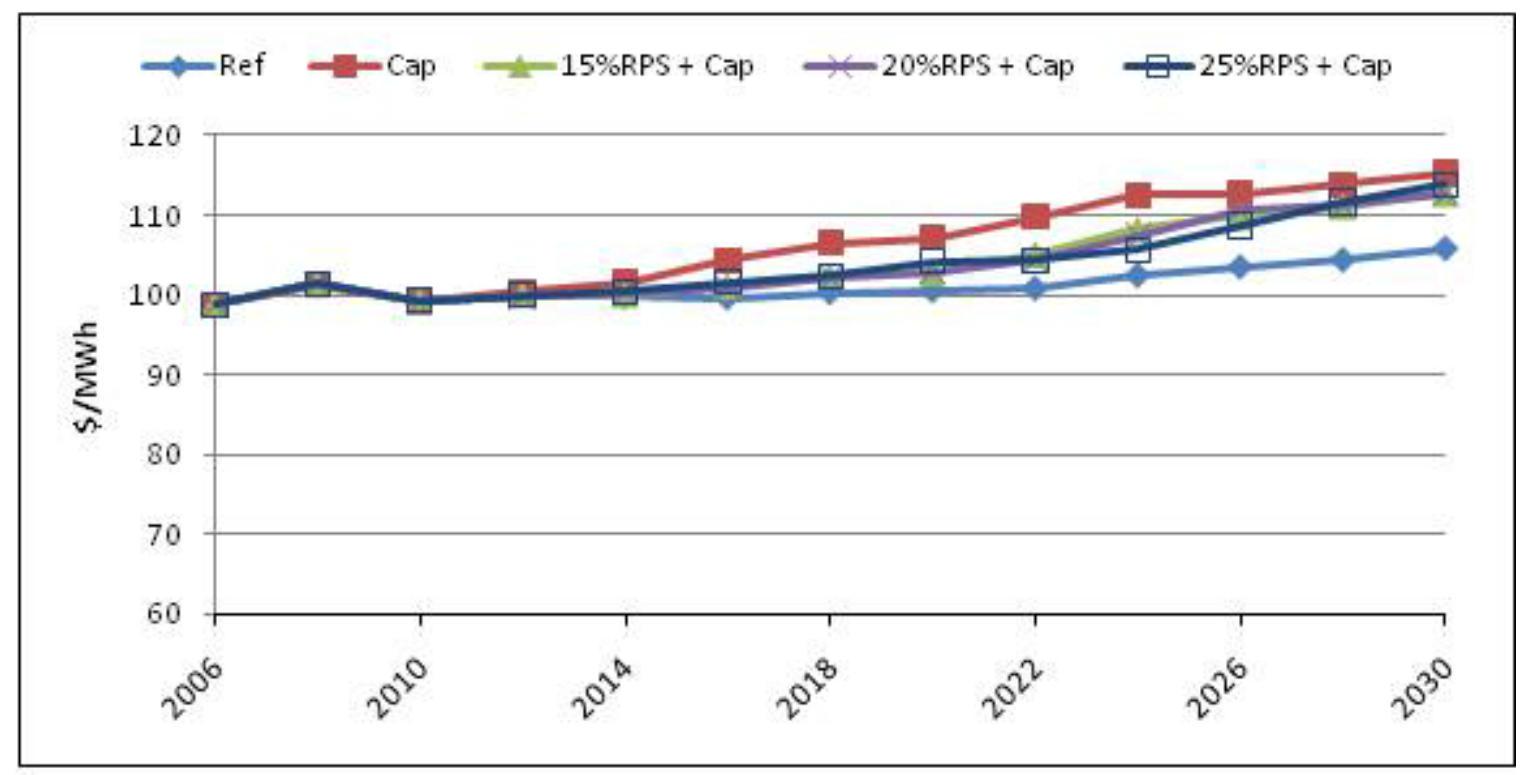

Figure 9. Electricity prices for cap and varying RPS targets (2009\$)

\section{Other Related Studies}

Although there are many published analyses of the Waxman-Markey bill, ${ }^{12}$ few focus on the combined impacts of a national RPS and cap-and-trade policy on the renewable energy sector. The Energy Information Administration published an analysis in July 2009 using the National Energy Modeling System (NEMS); it demonstrates the impact of policy details on renewable energy generation under a combined cap and RPS scenario (EIA 2009b). The Union of Concerned Scientists (UCS) in February 2010 also published an analysis using NEMS, primarily focusing on the consumer cost savings of a stronger RPS and a separate energy-efficiency resource standard (UCS 2010). Highlights from both analyses are summarized below.

\section{Energy Information Administration}

The EIA analysis included six main scenarios that explored differences in the use of carbon offsets and banking of carbon allowances to achieve the cap. Use of coal and natural gas declines in almost all cases, and renewable and nuclear energy serve as substitutes. In cases where no international carbon offsets are allowed, renewable and nuclear energy use increase substantially over

12. See, for example, those by the U.S. EPA, "EPA Analysis of the American Clean Energy and Security Act," June 2009, http://www.epa.gov/climatechange/economics/economicanalyses.html\#hr2454 (accessed May 11, 2010); the Congressional Research Service, "Climate Change: Costs and Benefits of the Cap and trade Provisions of H.R. 2454," Parker, L. and Yacobucci, B. (September 2009), http://energy.senate.gov/public/ files/R40809.pdf (accessed May 11, 2010); and the Congressional Budget Office, "H.R. 2454 American Clean Energy and Security Act of 2009: Cost Estimate," June 2009, http://www.cbo.gov/ftpdocs/102xx/doc10262/hr2454.pdf (accessed May 11, 2010). 
the modeling period. The EIA finding of significant nuclear expansion over the period differs from our analysis, primarily due to differences in cost assumptions for new nuclear plants. ${ }^{13}$

Forecasted electricity prices in the EIA analysis increased slowly in all of the main scenarios, but rose more quickly after 2025 when the assumption that retail electricity providers would receive free allowances is phased out. In all of the EIA scenarios, the share of renewable generation exceeded the requirements of the combined efficiency and renewable electricity standard, meaning that the cap promotes renewable generation more than the RPS. It is instructive, however, to consider how policy design within the RPS and exemptions affects renewable energy generation across the cases.

Figure 10 highlights RPS compliance in the EIA analysis over time. The dashed red line shows qualifying renewable generation achieved in the standard Waxman-Markey case. The dashed black line is a reference case (no changes to policy). The bill has provisions that exempt small utilities from compliance (circles), allow new nuclear and CCS generation to be subtracted out of the denominator of total qualifying generation when calculating the RE percentage ${ }^{14}$ (triangles), and credit a portion of efficiency improvements to substitute for renewable generation (crosses). Therefore, although the nominal target for renewable energy is $20 \%$ in 2025 (diamonds), these exemptions collectively allow the target to be met with only $9 \%$ renewable energy.

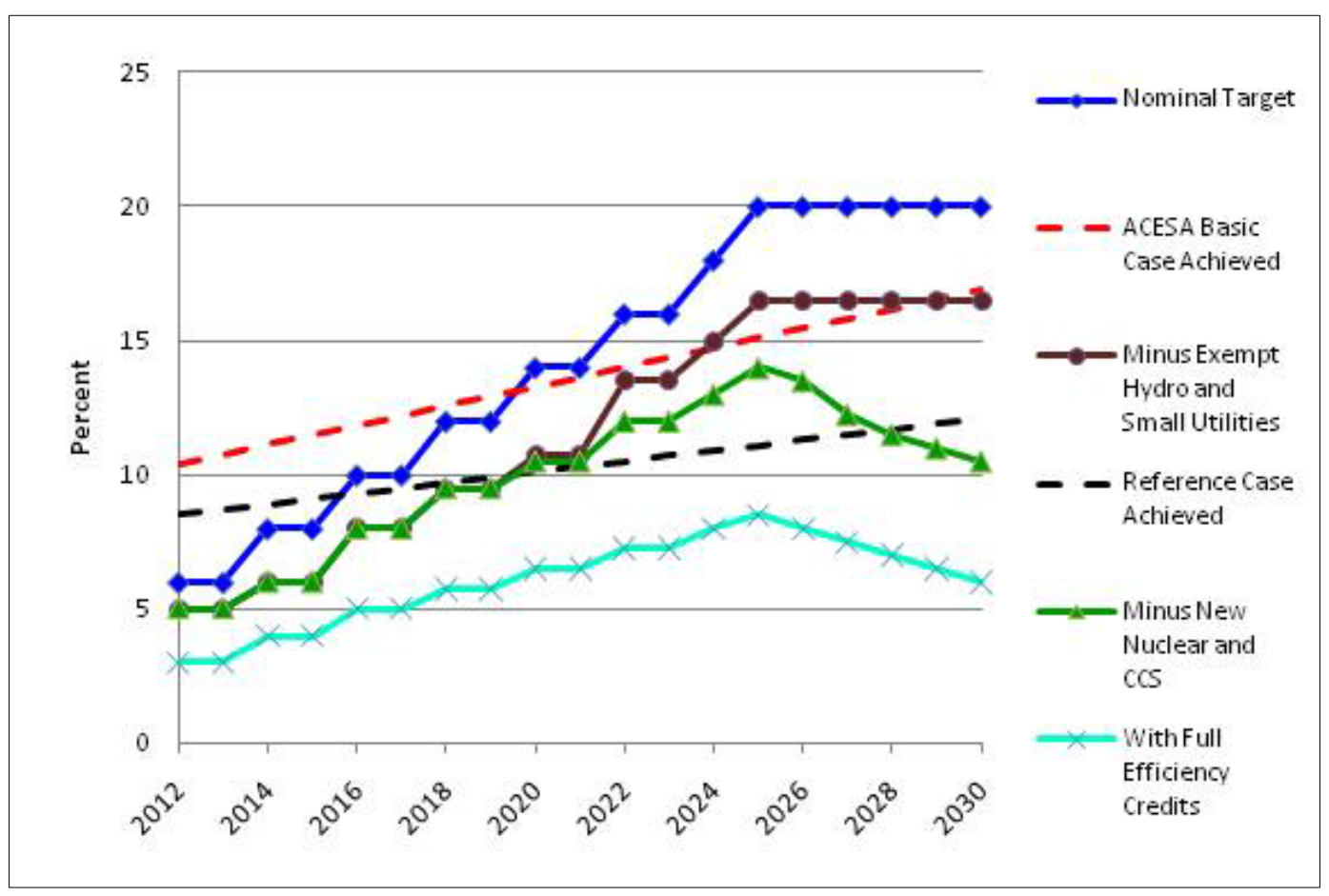

Figure 10. Renewable portfolio standard compliance in H.R. 2454

13. The EIA study uses overnight nuclear capital costs of $\$ 3,318 / \mathrm{kW}$ in 2008 , declining to $\$ 2372 / \mathrm{kW}$ in 2030 . This ReEDS analysis assumes steady overnight nuclear capital costs of $\$ 4,500 / \mathrm{kW}$.

14. The RES compliance calculation is the ratio of qualifying renewable energy in the numerator and qualifying total generation in the denominator. A smaller denominator reduces the amount of renewable energy required to reach compliance. 
The EIA analysis demonstrates that the policy details in how the RPS and cap-and-trade provisions are linked can have an impact on renewable energy markets. The three types of exemptions in the legislation allow easier compliance with the RPS target than would otherwise be the case. In other words, actual renewable electricity deployment in the American Clean Energy and Security Act of 2009 (ACES Act) basic case after 2020 would be pushed from the red dashed line to the blue diamond line without the exemptions.

\section{Union of Concerned Scientists}

In February 2010, the Union of Concerned Scientists released a four-page summary of an analysis of Waxman-Markey that contained a comparison to a stronger RPS and separate energyefficiency resource standard. ${ }^{15}$ The analysis also used NEMS and the same cost and performance assumptions as the EIA analysis described above, but increased the nominal RPS to $25 \%$ by 2025 and set the separate energy-efficiency resource standard at $10 \%$ by 2020 . The three types of exemptions in the RPS provisions also were removed, resulting in non-hydro renewable energy generation expanding to $22.4 \%$ of total U.S. electricity sales by 2030 .

Most of the UCS summary focuses on projected cost savings that consumers would see due to lower natural gas and electricity prices compared to EIA's ACES Act basic scenario. There is less detail provided regarding how the cap-and-trade and RPS provisions interact, although the study clearly shows that, by removing the three types of exemptions noted in the EIA analysis above (which also serve to link the RPS to the cap), greater energy supply diversity is achieved. ${ }^{16}$ The UCS study also found that a more aggressive RPS and separate efficiency policy reduced carbon dioxide allowance prices. The UCS found a 4.4\% reduction in carbon dioxide allowances prices in their more aggressive RPS and efficiency policy case as compared to the EIA analysis of the Waxman-Markey bill. For 2030, the UCS determined a carbon dioxide allowance price of $\$ 61.40$ per ton under the more aggressive RPS and efficiency policy scenario as compared to $\$ 64.50$ per ton under the EIA's analysis of the Waxman-Markey bill. Figure 11 is drawn from the UCS study and shows new wind energy playing the dominant role through 2012 before leveling off until 2020 . New biomass generation is expected to grow rapidly through 2030 .

15. This analysis, "A Better Climate Bill: Raising Efficiency and Renewable Electricity Standards Increases Consumer Benefits," is available at http://www.ucsusa.org/clean_energy/solutions/big_picture solutions/a-better-climate-bill.html (accessed May 11, 2010). Additional details from the analysis are available on the Union of Concerned Scientists Web site.

16. This finding is illustrated on slide 7 of the "Presentation Slides" that accompany the news release. See http://www.ucsusa.org/assets/documents/clean_energy/slides-a-better-climate-bill.pdf (accessed May 11, 2010). 


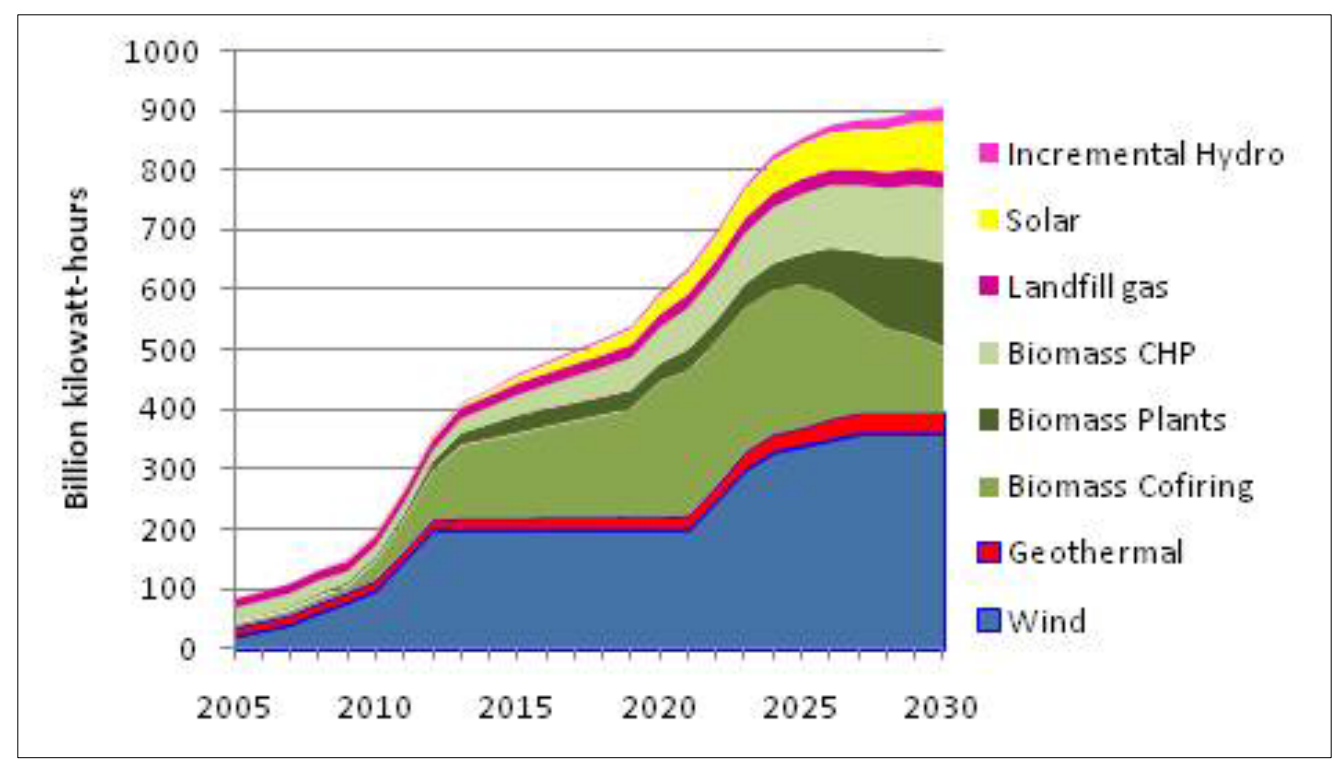

Figure 11. Renewable energy generation mix in the UCS study

\section{Simultaneous Implementation of a Carbon Cap and a Renewable Portfolio Standard: Design Issues}

This section examines issues surrounding the simultaneous implementation of a carbon cap and a RPS, and the design issues that could concern policymakers.

\section{Policy Objectives and Assessing the Need for Combined Policies}

Although carbon caps are designed primarily to reduce greenhouse gas emissions, RPS polices are designed to increase the amount of renewable energy in the generation mix. The policies can be motivated by environmental benefits - such as global climate change or reductions in air pollutants - but also can be motivated by jobs and economic development benefits investment opportunities, and resource diversity (Gonzalez 2007). State RPS policies focus on environmental benefits as well as the co-benefits of renewable energy.

- Hawaii's RPS legislation states that "renewable energy resources offer Hawaii important job creation, environmental protection, and energy security benefits" (Holt and Wiser 2007).

- Montana's RPS legislation specifies that "fuel diversity, economic and environmental benefits from renewable energy production accrue to the public at large" (Holt and Wiser 2007).

- Washington's renewable energy initiative promotes renewable energy as it will "stabilize electricity prices ... provide economic benefits . . . create high[-]quality jobs . . provide opportunities for training apprentice workers ... protect clean air and water" (Holt and Wiser 2007).

Although renewable energy is one mechanism to reduce greenhouse gas emissions, other methods of achieving emissions reductions are through energy efficiency, increased fuel economy, and carbon sequestration. Emissions caps attempt to encourage the combination of 
actions to meet emissions targets within covered sectors at the least cost. For this reason, some have questioned the need for an RPS if caps are adopted.

Fischer and Preonas (2010) note that rationales for implementing supplementary renewable energy technology policies in conjunction with market-based carbon emissions policies include avoiding technology lock-in by encouraging research and development, addressing knowledgebased or technology-based market failures that limit the effectiveness of market-based emissions policies, gaining competitive advantages of providing strong early support for technologies that have significant export potential, as well as obtaining the other benefits of the renewable energy technologies.

Others have concluded that a combination of policies is ideal for minimizing long-term risk of not meeting emissions goals (CPUC 2008a). For example, the California Public Utilities Commission (CPUC) and the California Energy Commission (CEC) recognized in their collaborative proceeding to inform the California Air Resources Board on measures and strategies for reducing greenhouse gas emissions that a GHG market can be a backstop for regulatory programs, such as its RPS. In the CPUC's proposed decision, it recognized that:

While regulatory programmatic strategies are the foundation of our recommended strategy, a market would provide a backstop to the programs, should they fail to deliver sufficient GHG emissions reductions. Having a binding cap on emissions can ensure that the goals are met and that the ingenuity and creativity of the private sector are unleashed to find new and lower-cost alternatives to providing reductions. (CPUC 2008a)

As modeling results show, although sufficiently stringent emissions cap levels can drive development of renewable energy generation, an RPS can provide additional certainty to the market. Because an RPS dictates how much and when renewable energy must be deployed, it creates a concrete goal for the business community with respect to the renewable energy generation required. Such a policy could allow industries to develop manufacturing, infrastructure, and human capital in advance of what would be determined through a market mechanism such as a cap-and-trade system. Similarly, under more modest emissions cap levels RPS policies could encourage greater renewable energy development in the near term, which can assist the industry in building infrastructure and manufacturing to meet more-stringent emissions goals in the longer term. RPS policies also can provide more long-term stability to encourage technology advancement. Administering emissions cap and RPS policies, however, might add some administrative costs. With respect to costs to consumers, the modeling results indicate that the overall impact on electricity prices of adding an RPS to an emissions cap is not significant.

\section{Recent Experience with Simultaneous Implementation of Carbon Dioxide Caps and Renewable Portfolio Standards}

To date, there is limited experience in implementing a cap-and-trade policy with an RPS. Although the European Union's ETS operates in conjunction with renewable portfolio standards in individual countries, European countries have focused more on feed-in tariff policies than renewable portfolio standards to encourage renewable energy development. In the United States, implementation of both a cap-and-trade system and RPS polices so far has been limited to the Regional Greenhouse Gas Initiative. 


\section{Regional Greenhouse Gas Initiative}

In the United States, implementation of both a cap-and-trade system and RPS polices has so far been limited to the northeast and mid-Atlantic states that participate in the Regional Greenhouse Gas Initiative. The RGGI's cap took effect in 2009, and requires a $10 \%$ reduction by the power sector in 10 states (Connecticut, Delaware, Maine, Maryland, Massachusetts, New Hampshire, New Jersey, New York, Rhode Island, Vermont) by 2018. All of the participating states have RPS policies in place except for Vermont, which has a nonbinding renewable goal of having renewable energy meet any increase in retail sales by 2012 , and having $20 \%$ renewable energy (including combined heat and power) by 2017. The 9 other RGGI states have standards ranging from 10\% new renewables by 2017 (Maine) to 23.5\% renewables by 2021 (New Jersey).

The RGGI cap is relatively modest in its stringency, requiring emissions to remain stable between 2009 and 2014 and reductions to begin in 2015. As a result, the price of allowances has remained low, at roughly $\$ 2$ to $\$ 3$ per short ton, which has not provided a strong enough market signal to encourage increased renewable energy development. A portion of the revenues from the auction of carbon dioxide allowances, however, is used to support energy efficiency and renewable energy. Revenues from auctions completed as of December 2009 total $\$ 432.8$ million and are divided between the 10 participating states. States use revenues to sponsor different programs, with at least $25 \%$ to be used for energy efficiency and renewable energy. The program has been in place for slightly more than a year, so there is not enough experience to determine the extent to which renewable energy has been promoted by the revenues.

The RGGI does provide a model for how RECs can operate with carbon credits. Under the RGGI, RECs and carbon credits remain separate commodities. Renewable energy generators are not granted allowances under the RGGI program and do not need to purchase them through auctions; therefore, renewable generators do not participate in the carbon dioxide allowance market. The generators retain RECs which they can sell to utilities or load-serving entities with RPS obligations; the RGGI program does not interfere with that ability.

\section{European Union Emissions Trading System}

The European Union's Emissions Trading System (ETS) has been operating longer than RGGI. In the EU, however, there is less reliance on RPS as a policy-support mechanism for renewable energy; rather, there is greater reliance on feed-in tariffs. Adoption of a European Renewable Energy Sources directive - approved by the European Parliament in December 2008 - creates a European standard of $20 \%$ renewable energy by 2020 . Countries each have their own targets which average to $20 \%$ renewable energy in 2020 . Each country is responsible for developing a national renewable energy action plan to determine how to reach its targets (EurActiv 2009).

The United Kingdom provides an example of how REC and carbon markets can be structured to complement each other. Currently, in the United Kingdom - which has a renewable portfolio standard ("renewable obligation") - firms which generate RECs in excess of their obligation can convert them to carbon credits to be used in the Emissions Trading Scheme. Carbon offsets, however, cannot be used to comply with the renewable portfolio standard (Gonzales 2007). Renewable energy generators are not allocated allowances under the EU ETS scheme and do not 
need to purchase them through auctions. ${ }^{17}$ Renewables therefore do not directly participate in carbon markets.

In its early stages, the ETS failed to encourage renewable energy investment. This in part was due to the over-allocation of emissions allowances which led to low prices. The quantity of emissions allowances allocated was based on projected future needs and, in 2005, allowances exceeded emissions by approximately 80 million tons, or about $4 \%$ of the EU's intended maximum level (Ellerman and Buchner 2007). Over-allocation led to a sharp drop in allowance prices, creating volatility in the market; this could discourage investment in renewable energy (Blanco and Rodrigues 2008).

\section{Design and Implementation Considerations}

Although RPS and emissions caps can be (and have been) implemented simultaneously, the policy design details and implementation can vary depending on policy goals. We explore some of the policy design and interaction considerations in this section, with a particular focus on the interaction between carbon dioxide allowances and RECs.

\section{Renewable Energy Certificate and Carbon Dioxide Allowance Interaction}

Implementing a cap-and-trade system along with a RPS can raise questions surrounding the interaction of RECs and carbon allowances. If cap-and-trade policies allocate allowances to renewable energy generators and those generators also can sell RECs into compliance RPS markets, then renewable energy generators could participate in both carbon and REC markets and obtain revenues from the sale of both, unless they are restricted from doing so. If the goal of the RPS policy is to reduce overall carbon dioxide emissions, then policy makers should consider whether RECs used to achieve RPS compliance must be bundled with any allocated carbon dioxide allowances. If such a requirement is instituted, it would mean that the RPS would result in emissions reductions beyond the level specified by the emissions cap.

This is not a concern if a cap-and-trade system does not allocate allowances to renewable energy generators. The two markets - REC and carbon — would operate independently. Renewable energy generators could sell only RECs, and their operation would not affect overall GHG emissions levels (which would be fixed by the cap). Similarly, if allowances are auctioned to emitters, then the two markets would operate independently. Such is the case with the Regional Greenhouse Gas Initiative and in the EU Emissions Trading Scheme.

The Waxman-Markey bill does not allocate carbon allowances to renewable energy generators. This eliminates the possibility of selling a REC and a carbon allowance from the same megawatt hours (MWh) of generation. In contrast, the most recent draft of the Kerry-Boxer bill (S. 1733, dated late 2009) allocates $2.5 \%$ of the allowances granted for state and local investment in energy efficiency and renewable energy to renewable energy producers that generate more than $20 \mathrm{MW}$, based on their output and the technology used. Final regulations are delegated to the administrator (EPA) to promulgate. Such a provision would allow renewable energy generators to participate in both the carbon market and the RPS market, depending on the specifics of any final regulations. A renewable energy generator could sell allowances under a carbon cap-and-

17. The European Union is moving toward greater auctioning of allowances. In Phase II of the ETS (2008-2012), auctioning is limited to $10 \%$ of allowances. For Phase III, which begins in 2013, however, the EU is developing regulations that could result in more than half of the allowances in 2013 to be auctioned (European Commission 2009). 
trade system and also could sell RECs into compliance RPS markets, unless the state RPS (or any potential federal RPS) restricted this ability.

Some states have developed RPS rules requiring that any emissions allowances (including carbon allowances) granted to renewable energy generators must be bundled (or retired) with a REC that is used for RPS compliance. Under this method, the carbon dioxide allowances must be taken out of circulation (retired) and cannot be sold to another emitter, thereby reducing allowable emissions. The RPS administrators do this to ensure that the RPS results in GHG emissions reductions (or carbon dioxide benefits) in addition to those required by the cap. Many RPS policies are designed (at least in part) to address GHG emissions and climate change and some policies include specific language stating that goal. States often also have other objectives, however, such as job creation, local economic benefits, energy security and diversification of supplies, and other environmental benefits such as air quality. Thus, if a specific objective of the RPS is to create emissions benefits, then this approach would ensure that the RPS results in emissions benefits. This approach could be of particular interest to RPS administrators if a weak emissions cap is in place. If a very strict emissions cap is established, however, then the RPS could be viewed as one mechanism for meeting the emissions reductions goals of the cap.

As of late 2009, eight states have explicit provisions regarding whether GHG allowances must be retired with RECs used for RPS compliance, with five of those states requiring that any carbon allowances granted to the renewable energy generator must be retired with the REC. The majority (21 states and Washington, DC) either do not address allowance retirement or have vague language surrounding the attributes contained in the REC (Table 6). Examples of vague language include using terminology such as that compliance RECs include "all renewable and environmental attributes," "all environmental attributes," or "unspecified attributes."

Table 6. State Rules on Retiring Carbon Allowances with RECs Used for RPS Compliance (Holt 2009)

\begin{tabular}{|l|l|}
\hline Provision of Carbon Allowances & States \\
\hline $\begin{array}{l}\text { Carbon allowances, if granted, must be retired with the REC } \\
\text { used for RPS compliance. }\end{array}$ & Arizona, California, Colorado, New York, Washington \\
\hline $\begin{array}{l}\text { Carbon allowances, if granted, are not required to be retired } \\
\text { with the REC used for RPS compliance. }\end{array}$ & Delaware, North Carolina, Pennsylvania \\
\hline $\begin{array}{l}\text { Allowance retirement either is not addressed or } \\
\text { language is unclear }\end{array}$ & $\begin{array}{l}\text { Connecticut; Hawaii; Illinois; lowa; Kansas; Maine; Maryland; } \\
\text { Massachusetts; Michigan; Minnesota; Missouri; Montana; } \\
\text { Nevada; New Hampshire; New Jersey; New Mexico; Ohio; } \\
\text { Oregon; Rhode Island; Texas; Washington, DC; Wisconsin }\end{array}$ \\
\hline
\end{tabular}

In RPS regulations, statements about "attributes" in RPS rules generally do not distinguish between direct emissions attributes and avoided emissions. Direct emissions attributes refer to the zero emission attribute of wind generation, for example. Avoided emissions are those that are displaced when less fossil fuel is used to generate electricity when the wind plant operates. The former does not change as a result of carbon policy; the latter can be affected because avoided emissions reduced under a cap result in an increase in emissions elsewhere, up to the level of the cap, as a result of allowance trading (Holt 2009).

It also is important to note that, for RPS administrators, there could be concerns about the disposition of the emissions attributes of the renewable energy in both a pre-cap and post-cap 
market. The pre-cap concern is whether to allow generators to sell both a REC and a carbon offset (into voluntary markets) from the same megawatt hour of renewable generation. In a postcap market, the concern is whether any carbon allowances that could be conveyed to renewable generators through a regulatory cap-and-trade program should be retired when the REC is used for RPS compliance. In both cases, the basis of the decision is whether the RPS is designed to result in emissions benefits.

California specifically has addressed the issue of whether a REC represents avoided emissions attributes. Through its rulemaking process to implement its RPS, the California Public Utilities Commission considered whether the benefits from avoided emissions could be included in a REC. The CPUC recognized that there were benefits to including avoided emissions reductions in a REC but, at the same time, a REC used for compliance also should not be sold as a carbon offset in the voluntary market.

We agree ... that a REC logically should include the attribute of avoided fossil fuel emissions, since this is among the benefits renewable generation is intended to produce. We also agree ... that a REC used for RPS compliance should not be used as a GHG offset, because it is clear from the very definition of an offset that, once counted for RPS compliance (and thus "otherwise regulated"), a REC can have no GHG offset value (CPUC 2008b).

Although the CPUC decision addresses the question of whether a REC should represent avoided emissions, it primarily relates to the sale of carbon offsets from renewable energy in a pre-cap market. This is because renewable energy would not be eligible to provide carbon offsets under a cap-and-trade program that covers the electric sector. Offsets by definition must result in emissions reductions outside of the covered sector.

\section{Importing Renewable Energy Certificates from Outside of the Capped Region}

The creation of regional cap-and-trade systems that operate in conjunction with RPS policies can raise additional implementation issues. These issues do not arise in the case of a federal emissions cap, however.

The treatment of the imports of RECs or renewable energy from non-capped regions can be an issue for regional cap-and-trade systems. Renewable energy certificates or renewable energy generation from outside the capped region can have avoided carbon emissions benefits by displacing fossil-fuel generation. For regional cap-and-trade systems that account for imports, this can be an issue with respect to carbon accounting. The treatment also can have implications regarding the value of RECs generated both from within the capped region and from outside of the capped region.

The issue of importing RECs has arisen in developing rules for the Western Climate Initiative, a cap-and-trade program under development by a number of Western U.S. states and some Canadian provinces. The WCI has proposed including electricity imported from outside the capped region, making it the first jurisdictional deliverer of power subject to the cap. Emissions values would be assigned to the imported power based on the emissions from a specific power plant or using the default emissions rate. Treatment of imports in this manner in a regional cap raises questions of how to treat RECs and renewable energy imports from uncapped regions to avoid "double counting" the emissions benefits of the renewable energy. Double counting can be 
avoided by allowing either the null power ${ }^{18}$ (the underlying commodity electricity resulting once RECs are sold separately) associated with imported renewable power or the RECs used with other power to receive zero GHG attribution—not both (Murtishaw 2008).

Murtishaw (2008) lists several options for treating imports of renewable energy into the capped region.

- Require the RECs to remain bundled with the imported electricity from the renewable generator and then retire the RECs.

- Pair RECs (which are granted the zero emission attribute) with null power (or unspecified power) and assign a default emission rate to the null power.

- Assign a zero emission attribute to the renewable electricity imported and do not count the RECs in GHG accounting.

Each of these options has implications for REC markets both within and outside the capped region. The first option would limit the use of RECs by requiring bundling with the power. The second potentially creates RECs with different values within the capped region and outside of it, because the REC would provide emissions benefits in addition to counting toward an RPS. Some owners of generation might be hesitant to split the REC from the underlying electricity because an emissions "penalty" would be applied to the power. The third option could result in the REC being used for RPS compliance in an uncapped state and the underlying electricity also could receive an emission benefit. This also would have implications for RECs sold in voluntary markets in which the purchaser of a REC from the uncapped region might wish to retain the emissions benefits. As of January 2010 these options are still under consideration, but WCI rules on this issue are expected in the first half of 2010.

\section{Resource Eligibility and "Double Dipping"}

Another issue that could arise when implementing both an RPS and a carbon emissions cap-andtrade program simultaneously is that some resources might be eligible to participate in both markets. For example, resources that qualify as renewable energy generation for RPS compliance and also result in the GHG emissions benefits through the destruction or avoidance of methanewhich is 23 times more potent as a GHG than carbon dioxide - could be eligible to sell both the RECs associated with the renewable electricity generation and the GHG offsets associated with the methane reduction. This might be the case for landfill gas, biogas, and certain bioenergy facilities. Policy makers could choose to allow a double benefit, particularly if they see the need to provide a greater incentive to these types of projects. This has been the case in the RGGI states so far. They could also choose to design RPS or cap-and-trade regulations to prevent the double benefit.

\section{Trading and Tracking}

For RPS markets in particular, there could be benefit to adding environmental tradable commodities (such as carbon) that could lead to the development of additional exchanges and trading platforms to encourage greater transparency and access to market data. Because RPS

18. The term "null power" refers to the commodity electricity associated with an increment of renewable energy in which the renewable energy attributes or RECs have been sold. The remaining "null power" does not retain the attributes of renewable energy, such as its zero emissions profile. Rather, it often is considered to have the emissions profile of the system's electricity mix (the average of all electric-generation sources in the system or region). The renewable energy attributes (e.g., zero-emissions benefits) are retained by the purchaser of the REC. 
markets have been relatively small in volume to date, the addition of a larger carbon-trading market could provide additional support.

Separate tracking systems likely will be used to track RECs for compliance with an RPS and track carbon allowances for a carbon cap-and-trade system. If carbon allowances are not granted to renewable energy generators then tracking is simplified; the RPS and the cap-and-trade program would operate separately. If renewable energy generation is granted carbon dioxide allowances, such as under the Kerry-Boxer bill, however, then there might be a need to track the disposition of the allowance and the REC, because some states have indicated that both must be bundled for the REC to be used for RPS compliance. In such situations, tracking systems would have to track whether the allowance has been retired when the REC is used for RPS compliance. This ideally would involve some communication between the RPS and carbon tracking systems for verification.

\section{Summary and Conclusions}

This analysis used the ReEDS model to evaluate the effects of a base emissions cap - similar to the Waxman-Markey cap - with offsets and banking, and with both a 20\% lower (less stringent) and $20 \%$ higher (more stringent) emissions cap. It also examined several RPS scenarios, including a $15 \%, 20 \%$, and $25 \%$ renewable energy requirement by 2020 , with the latter two scenarios increasing $1 \%$ annually through $2030 .{ }^{19}$ The ReEDS model was used to analyze various combinations of these policies to determine the impacts on the electric generation mix, carbon dioxide emissions levels, and electricity prices through 2030. The key findings are listed below.

- A carbon emissions cap and an RPS can be complementary policies that can achieve similar ends, although one policy is designed to reduce carbon emissions and the other is designed to increase renewable generation. In some cases, carbon caps have been implemented as backstops to ensure that emissions-reduction goals are met, together with relying on the implementation of technology and sector-specific policies such as RPS, efficiency standards, and other policies to encourage specific low-carbon solutions.

- A base cap alone drives significant renewable generation but at higher electricity prices than scenarios that include load reduction from energy efficiency. The cap alone case results in 19\% non-hydro renewable energy generation in 2020 and $40 \%$ in 2030 . When the cap is combined with load reduction from energy efficiency, the fraction of non-hydro renewable generation is $16 \%$ and $38 \%$ in 2020 and 2030, respectively. The scenarios that include load reduction achieved through energy-efficiency measures minimize electricity price impacts. For example, in 2020, the electricity price of the cap alone case is $4 \%$ higher than the case of the cap with load reduction from efficiency. It is important to note, however, that the energy-efficiency measures considered could have costs that are not captured in the analysis, including costs (such as those to building owners) that are not reflected in electricity prices. The benefits of efficiency measures in terms of bill savings are also not analyzed.

19. The scenarios evaluated are more stringently than in most recent legislative proposals because they do not incorporate exclusions that are contained in recently proposed bills. 
- A 25\% RPS results in similar emissions levels as the base cap in the near term at similar electricity price. The adoption of a 25\% RPS along with efficiency measures would put the electricity sector on a trajectory to meet the base emission cap levels in the 2020 timeframe at a similar electricity price. An RPS, however, does not provide a carbon price signal that would influence longer-term investment decisions based on a carbon-emissions basis or provide the same level of certainty of emissions reductions, particularly if demand increases. Renewable portfolio standards primarily address the contribution of renewable generation in the resource mix without focusing on the mix of coal, gas, and other technologies. The emissions benefits also are similar only in the next decade or so; emissions levels diverge after the 2020 timeframe, when the cap scenarios lead to less coal generation and, consequently, lower emissions than the $25 \%$ RPS scenario.

- Renewable portfolio standards combined with emissions caps could drive renewable energy generation beyond that achieved by emissions caps, particularly in the near term. The RPS targets considered in the analysis when combined with emissions caps and efficiency drive significant additional renewable generation in the 2015-2020 timeframe, except in the low-(15\%) RPS case combined with a cap. In the 2030 timeframe, the emissions cap drives significant renewable generation, generally greater than required by the RPS targets considered. The modeling conducted here does not capture the investment certainty that RPS policies could provide through fixed targets - which can be important, particularly for achieving greater future penetration levels, even when caps are present.

- Combining an RPS with a base cap does not lead to substantially greater electricity prices. Incorporating higher RPS targets in conjunction with a base cap results in slight electricity price differences. The RPS and efficiency (no cap) scenarios also result in electricity prices below the reference case in the 2025-2030 timeframe. For example, the electricity price for the $25 \%$ RPS plus efficiency is $2 \%$ below the reference case in 2030 .

- The addition of an RPS and efficiency to a base cap results in a reduction in carbon dioxide $\left(\mathrm{CO}_{2}\right)$ allowance prices. Our analysis shows a substantial reduction in $\mathrm{CO}_{2}$ allowance prices in most years when an RPS and load-reduction measures are added to a base cap, because compliance costs are shared by the other policies and some costs are shifted to the REC price. The effect is more pronounced for a 25\% RPS than for lower RPS levels. Similarly, our analysis shows a substantial reduction in REC prices when an emissions cap also is placed on the electric sector, where the cap shares a portion of the burden in meeting the RPS.

RPS and cap-and-trade policies have been implemented simultaneously and there are no regulatory or legal barriers to doing so. There has been some limited experience in implementing both emissions caps and RPS policies simultaneously in both Europe as well as in the Regional Greenhouse Gas Initiative of the northeast and mid-Atlantic states.

Design details are specific to each policy and its goals, and determine the level of interaction that results when implementing each policy simultaneously. The design of emissions caps and RPS 
can raise questions with respect to how RECs and carbon dioxide allowances interact, particularly if allowances are allocated to renewable generation under the emissions cap. If an RPS has a goal of affecting emissions levels, policy makers might want to consider interactions among the tradable instruments. Other issues to address include how regional emission caps can treat renewable generation from outside of the region, and whether some resources could be eligible to participate in both markets. 


\section{References}

Blanco, M.I.; Rodrigues, G. (2008). "Can the Future EU ETS Support Wind Energy Investments?” Energy Policy (36:4); pp. 1509-1520.

California Public Utilities Commission (CPUC 2008a). Proposed Decision of Commissioner Peevy (mailed 9/12/2008). Agenda ID\# 7922 (Rev. 1) 10/16/2008 Item \#34. Rulemaking 06-04009 (filed April 13, 2006). http://docs.cpuc.ca.gov/word_pdf/AGENDA_DECISION/92288.pdf. Accessed February 5, 2010.

California Public Utilities Commission (CPUC 2008b). CPUC Rulemaking 06-02-012, Decision 08-08-028 (August 21, 2008). Decision on Definition and Attributes of Renewable Energy Credits for Compliance with the California Renewables Portfolio Standard. http://docs.cpuc.ca.gov/word pdf/FINAL_DECISION/86954.pdf. Accessed February 5, 2010.

del Río González, P. (2007) “The Interaction Between Emissions Trading and Renewable Electricity Support Schemes. An Overview of the Literature." Mitigation and Adaptation Strategies for Global Change (12:8); pp. 1363-1390.

Ellerman, D.A.; Buchner, B.K. (2007). "The European Union Emissions Trading Scheme: Origins, Allocation, and Early Results." Review of Environmental Economics and Policy (1:1); pp. 66-87.

Energy Information Administration (EIA 2009a). An Updated Annual Energy Outlook 2009 Reference Case Reflecting Provisions of the American Recovery and Reinvestment Act and Recent Changes in the Economic Outlook, April. SR/OIAF/2009-03 http://www.eia.doe.gov/ oiaf/servicerpt/stimulus/index.html. Accessed May 10, 2010.

Energy Information Administration (EIA 2009b). Energy Market and Economic Impacts of H.R. 2454, the American Clean Energy and Security Act of 2009. http://www.eia.doe.gov/ oiaf/servicerpt/hr2454/index.html. Accessed May 10, 2010.

European Commission (2009). "Emission Trading System (EU ETS) Auctioning." http://ec.europa.eu/environment/climat/emission/auctioning_en.htm\#3. Accessed February 4, 2009.

EurActiv.com (2010). "EU Renewable Energy Policy.” http://www.euractiv.com/en/energy/eurenewable-energy-policy/article-117536. Accessed May 12, 2010.

Fischer, C. and Preonus, L. 2010. "Combining Policies for Renewable Energy: Is the Whole Less than the Sum of its Parts?" Resources for the Future, Washington, DC.

http://www.rff.org/Publications/Pages/PublicationDetails.aspx?PublicationID=21041

Holt, E. (2009). "State REC Definitions: How They Vary, What It Means." Presented at the States Advancing RPS Webinar-Renewable Energy Credits: Definitions, Attributes and Markets. http://www.cleanenergystates.org/JointProjects/RPS/Holt_SARPS-8.pdf. Accessed May 10, 2010. 
Holt, E.; Wiser, R. (April 2007). The Treatment of Renewable Energy Certificates, Emissions Allowances, and Green Power Programs in State Renewables Portfolio Standards. Report prepared for Lawrence Berkeley National Laboratory, Berkeley, California. LBNL-62574.

Murtishaw, S. (2008). Electricity Subcommittee Discussion Paper on Renewable Portfolio Standards, Renewable Energy Certificates, and GHG Accounting. Western Climate Initiative.

Regional Greenhouse Gas Initiative, RGGI (2008). "Model Rule, 12/31/08" http://www.rggi.org/docs/Model\%20Rule\%20Revised\%2012.31.08.pdf. EurActiv (2009). Accessed May 12, 2010.

Union of Concerned Scientists (UCS) (February 2010). A Better Climate Bill: Raising Efficiency and Renewable Electricity Standards. http://www.ucsusa.org/clean energy/solutions/ big_picture_solutions/a-better-climate-bill.html. Accessed May 10, 2010.

U.S. Department of Energy (DOE) (2008). 20\% Wind Energy by 2030: Increasing Wind Energy's Contribution to the U.S. Electricity Supply, July http://www1.eere.energy.gov/ windandhydro/pdfs/41869.pdf. Accessed May 10, 2010.

U.S. Environmental Protection Agency (U.S. EPA June 2009). EPA Analysis of the American Clean Energy and Security Act of 2009 H.R. 2454 in the 111th Congress. http://www.epa.gov/ climatechange/economics/economicanalyses.html\#hr2454. Accessed May 10, 2010. 


\section{Appendix A. Summary Tables}

Table A-1. Electric Generation Mix with RPS/Cap Individually and Combined by Scenario and Year

\begin{tabular}{|c|c|c|c|c|c|c|c|c|c|c|}
\hline & \multicolumn{2}{|c|}{ Reference } & \multicolumn{2}{|l|}{ Cap } & \multicolumn{2}{|c|}{ 15\% RPS + Cap } & \multicolumn{2}{|c|}{$15 \%$ RPS } & \multicolumn{2}{|c|}{$25 \%$ RPS } \\
\hline & \begin{tabular}{|c|}
$\begin{array}{c}\text { Generation } \\
\text { (TWh) }\end{array}$ \\
\end{tabular} & $\%$ & \begin{tabular}{|c|}
$\begin{array}{c}\text { Generation } \\
\text { (TWh) }\end{array}$ \\
\end{tabular} & $\%$ & \begin{tabular}{|c|}
$\begin{array}{c}\text { Generation } \\
\text { (TWh) }\end{array}$ \\
\end{tabular} & $\%$ & \begin{tabular}{|c|}
$\begin{array}{c}\text { Generation } \\
\text { (TWh) }\end{array}$ \\
\end{tabular} & $\%$ & \begin{tabular}{|c|}
$\begin{array}{c}\text { Generation } \\
\text { (TWh) }\end{array}$ \\
\end{tabular} & $\%$ \\
\hline \multicolumn{11}{|c|}{2020} \\
\hline Hydro & 312 & $8 \%$ & 312 & $8 \%$ & 312 & $8 \%$ & 312 & $8 \%$ & 312 & $8 \%$ \\
\hline Gas-Total & 459 & $11 \%$ & 801 & $19 \%$ & 638 & $17 \%$ & 201 & $5 \%$ & 167 & $4 \%$ \\
\hline Gas-CT & 26 & $1 \%$ & 5 & $0 \%$ & 6 & $0 \%$ & 23 & $1 \%$ & 12 & $0 \%$ \\
\hline Gas-CC & 434 & $10 \%$ & 795 & $19 \%$ & 632 & $17 \%$ & 179 & $5 \%$ & 156 & $4 \%$ \\
\hline Gas-CCS & - & $0 \%$ & - & $0 \%$ & - & $0 \%$ & - & $0 \%$ & - & $0 \%$ \\
\hline Coal-Total & 2,226 & $54 \%$ & 1,419 & $35 \%$ & 1,487 & $39 \%$ & 2,075 & $54 \%$ & 1,744 & $45 \%$ \\
\hline Coal-Old & 2,214 & $54 \%$ & 1,415 & $34 \%$ & 1,483 & $39 \%$ & 2,071 & $54 \%$ & 1,740 & $45 \%$ \\
\hline Coal-New & 12 & $0 \%$ & 4 & $0 \%$ & 4 & $0 \%$ & 4 & $0 \%$ & 4 & $0 \%$ \\
\hline Coal-CCS & - & $0 \%$ & - & $0 \%$ & - & $0 \%$ & - & $0 \%$ & - & $0 \%$ \\
\hline Nuclear & 774 & $19 \%$ & 774 & $19 \%$ & 774 & $20 \%$ & 774 & $20 \%$ & 774 & $20 \%$ \\
\hline $\begin{array}{l}\text { Non-Hydro Renewables, } \\
\text { Total }\end{array}$ & 366 & $9 \%$ & 800 & $19 \%$ & 594 & $16 \%$ & 490 & $13 \%$ & 864 & $22 \%$ \\
\hline Wind, Onshore & 238 & $6 \%$ & 489 & $12 \%$ & 371 & $10 \%$ & 301 & $8 \%$ & 551 & $14 \%$ \\
\hline Wind, Offshore & 17 & $0 \%$ & 42 & $1 \%$ & 16 & $0 \%$ & 7 & $0 \%$ & 68 & $2 \%$ \\
\hline $\begin{array}{l}\text { Concentrating Solar } \\
\text { Power }\end{array}$ & 25 & $1 \%$ & 73 & $2 \%$ & 28 & $1 \%$ & 24 & $1 \%$ & 42 & $1 \%$ \\
\hline Biomass & 25 & $1 \%$ & 49 & $1 \%$ & 38 & $1 \%$ & 34 & $1 \%$ & 50 & $1 \%$ \\
\hline Geothermal & 39 & $1 \%$ & 124 & $3 \%$ & 115 & $3 \%$ & 96 & $2 \%$ & 124 & $3 \%$ \\
\hline Distributed PV & 22 & $1 \%$ & 23 & $1 \%$ & 26 & $1 \%$ & 29 & $1 \%$ & 29 & $1 \%$ \\
\hline Total Generation & 4,137 & & 4,106 & & 3,805 & & 3,852 & & 3,862 & \\
\hline \multicolumn{11}{|c|}{2030} \\
\hline Hydro & 312 & $7 \%$ & 312 & $7 \%$ & 312 & $7 \%$ & 312 & $7 \%$ & 312 & $7 \%$ \\
\hline Gas-Total & 547 & $12 \%$ & 535 & $12 \%$ & 496 & $12 \%$ & 412 & $10 \%$ & 157 & $4 \%$ \\
\hline Gas-CT & 35 & $1 \%$ & 35 & $1 \%$ & 2 & $0 \%$ & 11 & $0 \%$ & 4 & $0 \%$ \\
\hline Gas-CC & 512 & $11 \%$ & 512 & $11 \%$ & 494 & $12 \%$ & 402 & $9 \%$ & 153 & $4 \%$ \\
\hline Gas-CCS & - & $0 \%$ & - & $0 \%$ & 33 & $1 \%$ & - & $0 \%$ & - & $0 \%$ \\
\hline Coal-Total & 2,273 & $50 \%$ & 1,047 & $23 \%$ & 1,066 & $25 \%$ & 2,261 & $52 \%$ & 1,821 & $42 \%$ \\
\hline Coal-Old & 2,261 & $50 \%$ & 1,043 & $23 \%$ & 1,062 & $25 \%$ & 2,257 & $52 \%$ & 1,817 & $42 \%$ \\
\hline Coal-New & 12 & $0 \%$ & 4 & $0 \%$ & 4 & $0 \%$ & 4 & $0 \%$ & 4 & $0 \%$ \\
\hline Coal-CCS & - & $0 \%$ & 20 & $0 \%$ & 20 & $0 \%$ & - & $0 \%$ & - & $0 \%$ \\
\hline Nuclear & 741 & $16 \%$ & 749 & $17 \%$ & 741 & $17 \%$ & 741 & $17 \%$ & 741 & $17 \%$ \\
\hline $\begin{array}{l}\text { Non-Hydro Renewables, } \\
\text { Total }\end{array}$ & 649 & $14 \%$ & 1,813 & $40 \%$ & 1,606 & $38 \%$ & 592 & $14 \%$ & 1,289 & $30 \%$ \\
\hline Wind, Onshore & 372 & $8 \%$ & 749 & $17 \%$ & 708 & $17 \%$ & 327 & $8 \%$ & 599 & $14 \%$ \\
\hline Wind, Offshore & 28 & $1 \%$ & 483 & $11 \%$ & 353 & $8 \%$ & 13 & $0 \%$ & 140 & $3 \%$ \\
\hline $\begin{array}{l}\text { Concentrating Solar } \\
\text { Power }\end{array}$ & 61 & $1 \%$ & 185 & $4 \%$ & 120 & $3 \%$ & 33 & $1 \%$ & 133 & $3 \%$ \\
\hline Biomass & 37 & $1 \%$ & 197 & $4 \%$ & 195 & $5 \%$ & 40 & $1 \%$ & 225 & $5 \%$ \\
\hline Geothermal & 115 & $3 \%$ & 163 & $4 \%$ & 163 & $4 \%$ & 115 & $3 \%$ & 124 & $3 \%$ \\
\hline Distributed PV & 36 & $1 \%$ & 36 & $1 \%$ & 67 & $2 \%$ & 64 & $1 \%$ & 67 & $2 \%$ \\
\hline Total Generation & 4,522 & & 4,502 & & 4,274 & & 4,319 & & 4,320 & \\
\hline
\end{tabular}


Table A-2. Electric Generation Mix by Cap Level and Year

\begin{tabular}{|c|c|c|c|c|c|c|}
\hline & \multicolumn{2}{|c|}{ 25\%RPS + Low Cap } & \multicolumn{2}{|c|}{ 25\%RPS + Cap } & \multicolumn{2}{|c|}{ 25\%RPS + High Cap } \\
\hline & Generation (TWh) & $\%$ & Generation (TWh) & $\%$ & Generation (TWh) & $\%$ \\
\hline \multicolumn{7}{|c|}{2020} \\
\hline Hydro & 312 & $8 \%$ & 312 & $8 \%$ & 312 & $8 \%$ \\
\hline Gas-Total & 167 & $4 \%$ & 247 & $6 \%$ & 655 & $17 \%$ \\
\hline Gas-CT & 12 & $0 \%$ & 7 & $0 \%$ & 7 & $0 \%$ \\
\hline Gas-CC & 155 & $4 \%$ & 239 & $6 \%$ & 647 & $17 \%$ \\
\hline Gas-CCS & - & $0 \%$ & - & $0 \%$ & - & $0 \%$ \\
\hline Coal-Total & 1,748 & $45 \%$ & 1,648 & $43 \%$ & 1,208 & $32 \%$ \\
\hline Coal-Old & 1,744 & $45 \%$ & 1,644 & $43 \%$ & 1,204 & $32 \%$ \\
\hline Coal-New & 4 & $0 \%$ & 4 & $0 \%$ & 4 & $0 \%$ \\
\hline Coal-ccs & - & $0 \%$ & - & $0 \%$ & - & $0 \%$ \\
\hline Nuclear & 774 & $20 \%$ & 774 & $20 \%$ & 774 & $20 \%$ \\
\hline Non-Hydro Renewables, Total & 862 & $22 \%$ & 865 & $22 \%$ & 864 & $23 \%$ \\
\hline Wind, Onshore & 557 & $14 \%$ & 542 & $14 \%$ & 528 & $14 \%$ \\
\hline Wind, Offshore & 56 & $1 \%$ & 56 & $1 \%$ & 45 & $1 \%$ \\
\hline Concentrating Solar Power & 45 & $1 \%$ & 34 & $1 \%$ & 74 & $2 \%$ \\
\hline Biomass & 49 & $1 \%$ & 52 & $1 \%$ & 65 & $2 \%$ \\
\hline Geothermal & 126 & $3 \%$ & 152 & $4 \%$ & 124 & $3 \%$ \\
\hline Distributed PV & 29 & $1 \%$ & 29 & $1 \%$ & 27 & $1 \%$ \\
\hline Total Generation & 3,863 & & 3,845 & & 3,813 & \\
\hline \multicolumn{7}{|c|}{2030} \\
\hline Hydro & 312 & $7 \%$ & 312 & $7 \%$ & 312 & $7 \%$ \\
\hline Gas-Total & 321 & $7 \%$ & 302 & $7 \%$ & 655 & $15 \%$ \\
\hline Gas-CT & 3 & $0 \%$ & 1 & $0 \%$ & 8 & $0 \%$ \\
\hline Gas-CC & 318 & $7 \%$ & 301 & $7 \%$ & 647 & $15 \%$ \\
\hline Gas-CCS & 2 & $0 \%$ & 14 & $0 \%$ & 47 & $1 \%$ \\
\hline Coal-Total & 1,398 & $32 \%$ & 1,148 & $27 \%$ & 799 & $19 \%$ \\
\hline Coal-Old & 1,394 & $32 \%$ & 1,144 & $27 \%$ & 795 & $19 \%$ \\
\hline Coal-New & 4 & $0 \%$ & 4 & $0 \%$ & 4 & $0 \%$ \\
\hline Coal-Ccs & 2 & $0 \%$ & 6 & $0 \%$ & 19 & $0 \%$ \\
\hline Nuclear & 741 & $17 \%$ & 750 & $17 \%$ & 750 & $18 \%$ \\
\hline Non-Hydro Renewables-Total & 1,529 & $36 \%$ & 1,759 & $41 \%$ & 1,671 & $39 \%$ \\
\hline Wind, Onshore & 681 & $16 \%$ & 722 & $17 \%$ & 718 & $17 \%$ \\
\hline Wind, Offshore & 266 & $6 \%$ & 474 & $11 \%$ & 402 & $9 \%$ \\
\hline Concentrating Solar Power & 125 & $3 \%$ & 126 & $3 \%$ & 148 & $3 \%$ \\
\hline Biomass & 234 & $5 \%$ & 208 & $5 \%$ & 169 & $4 \%$ \\
\hline Geothermal & 155 & $4 \%$ & 163 & $4 \%$ & 167 & $4 \%$ \\
\hline Distributed PV & 67 & $2 \%$ & 67 & $2 \%$ & 67 & $2 \%$ \\
\hline Total Generation & 4,304 & & 4,289 & & 4,254 & \\
\hline
\end{tabular}


Table A-3. Electric Generation Mix by RPS Level with Cap and Year

\begin{tabular}{|c|c|c|c|c|c|c|}
\hline & \multicolumn{2}{|c|}{ 15\%RPS + Cap } & \multicolumn{2}{|c|}{ 20\%RPS + Cap } & \multicolumn{2}{|c|}{ 25\%RPS + Cap } \\
\hline & Generation (TWh) & $\%$ & Generation (TWh) & $\%$ & Generation (TWh) & $\%$ \\
\hline \multicolumn{7}{|c|}{2020} \\
\hline Hydro & 312 & $8 \%$ & 312 & $8 \%$ & 312 & $8 \%$ \\
\hline Gas-Total & 638 & $17 \%$ & 533 & $14 \%$ & 247 & $6 \%$ \\
\hline Gas-CT & 6 & $0 \%$ & 7 & $0 \%$ & 7 & $0 \%$ \\
\hline Gas-CC & 632 & $17 \%$ & 526 & $14 \%$ & 239 & $6 \%$ \\
\hline Gas-CCS & - & $0 \%$ & - & $0 \%$ & - & $0 \%$ \\
\hline Coal-Total & 1,487 & $39 \%$ & 1,531 & $40 \%$ & 1,648 & $43 \%$ \\
\hline Coal-Old & 1,483 & $39 \%$ & 1,527 & $40 \%$ & 1,644 & $43 \%$ \\
\hline Coal--New & 4 & $0 \%$ & 4 & $0 \%$ & 4 & $0 \%$ \\
\hline Coal-Ccs & - & $0 \%$ & - & $0 \%$ & - & $0 \%$ \\
\hline Nuclear & 774 & $20 \%$ & 774 & $20 \%$ & 774 & $20 \%$ \\
\hline Non-Hydro Renewables, Total & 594 & $16 \%$ & 672 & $18 \%$ & 865 & $22 \%$ \\
\hline Wind, Onshore & 371 & $10 \%$ & 420 & $11 \%$ & 542 & $14 \%$ \\
\hline Wind, Offshore & 16 & $0 \%$ & 2 & $1 \%$ & 56 & $1 \%$ \\
\hline Concentrating Solar Power & 28 & $1 \%$ & 45 & $1 \%$ & 34 & $1 \%$ \\
\hline Biomass & 38 & $1 \%$ & 43 & $1 \%$ & 52 & $1 \%$ \\
\hline Geothermal & 115 & $3 \%$ & 116 & $3 \%$ & 152 & $4 \%$ \\
\hline Distributed PV & 26 & $1 \%$ & 27 & $1 \%$ & 29 & $1 \%$ \\
\hline Total Generation & 3,805 & & 3,823 & & 3,845 & \\
\hline \multicolumn{7}{|c|}{2030} \\
\hline Hydro & 312 & $7 \%$ & 312 & $7 \%$ & 312 & $7 \%$ \\
\hline Gas-Total & 496 & $12 \%$ & 578 & $14 \%$ & 302 & $7 \%$ \\
\hline Gas-CT & 2 & $0 \%$ & 3 & $0 \%$ & 1 & $0 \%$ \\
\hline Gas-CC & 494 & $12 \%$ & 575 & $13 \%$ & 301 & $7 \%$ \\
\hline Gas-CCS & 33 & $1 \%$ & 13 & $0 \%$ & 14 & $0 \%$ \\
\hline Coal-Total & 1,066 & $25 \%$ & 1,032 & $24 \%$ & 1,148 & $27 \%$ \\
\hline Coal-Old & 1,062 & $25 \%$ & 1,028 & $24 \%$ & 1,144 & $27 \%$ \\
\hline Coal-New & 4 & $0 \%$ & 4 & $0 \%$ & 4 & $0 \%$ \\
\hline Coal-Ccs & 20 & $0 \%$ & 27 & $1 \%$ & 6 & $0 \%$ \\
\hline Nuclear & 741 & $17 \%$ & 750 & $18 \%$ & 750 & $17 \%$ \\
\hline Non-Hydro Renewables, Total & 1,606 & $38 \%$ & 1,555 & $36 \%$ & 1,759 & $41 \%$ \\
\hline Wind, Onshore & 708 & $17 \%$ & 680 & $16 \%$ & 722 & $17 \%$ \\
\hline Wind, Offshore & 353 & $8 \%$ & 303 & $7 \%$ & 474 & $11 \%$ \\
\hline Concentrating Solar Power & 120 & $3 \%$ & 144 & $3 \%$ & 126 & $3 \%$ \\
\hline Biomass & 195 & $5 \%$ & 198 & $5 \%$ & 208 & $5 \%$ \\
\hline Geothermal & 163 & $4 \%$ & 164 & $4 \%$ & 163 & $4 \%$ \\
\hline Distributed PV & 67 & $2 \%$ & 67 & $2 \%$ & 67 & $2 \%$ \\
\hline Total Generation & 4,274 & & 4,267 & & 4,289 & \\
\hline
\end{tabular}




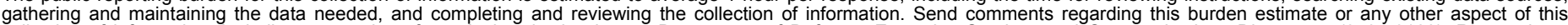

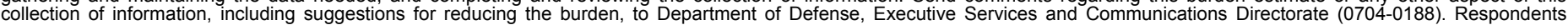

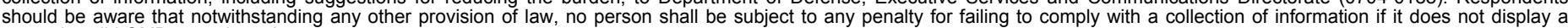

should be aware that notwithstanding

PLEASE DO NOT RETURN YOUR FORM TO THE ABOVE ORGANIZATION. May 2010

Technical Report

4. TITLE AND SUBTITLE

Evaluating Renewable Portfolio Standards and Carbon Cap

Scenarios in the U.S. Electric Sector

5a. CONTRACT NUMBER

DE-AC36-08-GO28308

5b. GRANT NUMBER

5c. PROGRAM ELEMENT NUMBER

6. AUTHOR(S)

L. Bird, C. Chapman, J. Logan, J. Sumner, and W. Short

5d. PROJECT NUMBER

NREL/TP-6A2-48258

5e. TASK NUMBER

SAO9.2038

5f. WORK UNIT NUMBER
7. PERFORMING ORGANIZATION NAME(S) AND ADDRESS(ES)

National Renewable Energy Laboratory

1617 Cole Blvd.

Golden, CO 80401-3393

9. SPONSORING/MONITORING AGENCY NAME(S) AND ADDRESS(ES)
8. PERFORMING ORGANIZATION REPORT NUMBER

NREL/TP-6A2-48258

10. SPONSOR/MONITOR'S ACRONYM(S) NREL

11. SPONSORING/MONITORING AGENCY REPORT NUMBER

12. DISTRIBUTION AVAILABILITY STATEMENT

National Technical Information Service

U.S. Department of Commerce

5285 Port Royal Road

Springfield, VA 22161

13. SUPPLEMENTARY NOTES

\section{ABSTRACT (Maximum 200 Words)}

This report examines the impact of various renewable portfolio standards (RPS) and cap-and-trade policy options on the U.S. electricity sector, focusing mainly on renewable energy generation. The analysis uses the National Renewable Energy Laboratory's Regional Energy Deployment System (ReEDS) model that simulates the least-cost expansion of electricity generation capacity and transmission in the United States to examine the impact of an emissions cap--similar to that proposed in the Waxman-Markey bill (H.R. 2454)--as well as lower and higher cap scenarios. It also examines the effects of combining various RPS targets with the emissions caps. The generation mix, carbon emissions, and electricity price are examined for various policy combinations to simulate the effect of implementing policies simultaneously.

\section{SUBJECT TERMS}

renewable portfolio standards; RPS; carbon cap scenarios; electric sector; cap-and-trade policy; cap and trade; renewable energy; Regional Energy Deployment System model; ReEDS; NREL; Lori Bird; Walter Short; Caroline Chapman; Jeff Logan; Jenny Sumner; analysis; energy analysis; policy analysis; Waxman-Markey bill; renewable energy certificate; REC; greenhouse gas emissions; GHG

\begin{tabular}{|l|l|l|l|l|}
\hline \multicolumn{3}{|l|}{ 16. SECURITY CLASSIFICATION OF: } & $\begin{array}{c}\text { 17. LIMITATION } \\
\text { OF ABSTRACT }\end{array}$ & $\begin{array}{c}\text { 18. } \\
\text { NUMBER } \\
\text { OF PAGES }\end{array}$ \\
\hline $\begin{array}{l}\text { a. REPORT } \\
\text { Unclassified }\end{array}$ & $\begin{array}{c}\text { b. ABSTRACT } \\
\text { Unclassified }\end{array}$ & $\begin{array}{l}\text { c. THIS PAGE } \\
\text { Unclassified }\end{array}$ & $\begin{array}{c}\text { UL } \\
\end{array}$ &
\end{tabular}

19a. NAME OF RESPONSIBLE PERSON

19b. TELEPHONE NUMBER (Include area code) 